\title{
XXIII.
}

\section{Ueber die Verwandtschaft der hämatogenen und autochthonen Pigmente und deren Stellung. zum sogenannten Hämosiderin.}

\author{
Von Dr. Martin B. Schmidt, \\ Assistenten am pathologischen Institut zu Heidelberg.
}

Jie von Virchow ${ }^{1}$ ) herrührende Unterscheidung zweier Formen hämatogenen Pigmentes galt ursprünglich nur der Norphologie. Verschärft wurde der Gegensatz erst, als sich herausstellte, dass $z$ wischen dem körnigen und dem krystallinischen Pigment auch chemische Differenzen obwalten: Der Eisengehalt, welchen zuerst F. Arnold ${ }^{2}$ ) in der Zeit, bevor man das Hämatoidin als Derivat des Blutfarbstoffs kannte, als Eigenthümlichkeit aller normalen und pathologischen Pigmente aufgestellt hatte, wurde von Perls ${ }^{3}$ ) an körnigem Pigment notorisch hämatogenen Ursprungs durch mikrochemische Reaction mittelst des Ferrocyankali-Salzsäuregemisches durchgehends constatirt; dagegen blieb dieselbe Reaction für das Hämatoidin erfolglos in Uebereinstimmung mit Staedeler's Elementaranalyse, nach welcher dasselbe eisenfrei ist.

In nevester Zeit hat Neumann's ${ }^{4}$ ) Untersuchung ergeben, dass die beiden chemisch differenten Gebilde auch bei ihrer Entwickelung aus dem Hämoglobin getrennte Wege gehen, und dass diese chemische und genetische Verschiedenheit sich meist mit der morphologischen deckt. Neumann fand, dass das eisenhaltige, meist körnige Pigment, das er als Hämasiderin bezeichnet,

1) Virchow, Die pathologischen Pigmente. Dieses Arehiv Bd. I. 1847.

2) F. Arnold, Lehrbuch der Physiologie. Bd. I. S. 99. 1836; und Handbuch der Anatomie. Bd. I. S. 142. 1845.

3) Perls, Nachweis von Eisenoxyd in gewissen Pigmenten. Dieses Arehiv Bd. 39. 1867.

4) Neumann,-- Beiträge zur Kenntniss der pathologischen Pigmente. Dieses Archiv Bd. 111. 1888. 


\section{8}

aus den rothen Blutkörperchen sich bildet, wenn dieselben in lebendes Gewebe extravasirt waren, dass dagegen die Entstehung des eisenfreien, meist krystallinischen Hämatoidins ein von vitaler Gewebsthätigkeit unabhängiger Zersetzungsprozess ist, welcher sich an Blutungen abspielt, die in lebensunfähiges Gewebe erfolgten.

Wenn diese Gesetzmässigkeit herrscht, so muss man annehmen, dass jedem rothen Blutkörperchen in dem Augenblick, wo es die Blutbahn verlässt, sein endliches Ziel vorgeschrieben wird, je nach der Intensität des Stoffwechsels, dem es ausgesetzt ist, und dass die Möglichkeit des Uebergangs der einen Form in die andere ausgeschlossen bleibt.

Eine reiche Ausbeute an Hämosiderin liefern Milz, Knochenmark und Leber von Hunden und Kaninchen. Ist die Menge desselben schon im physiologischen Zustande eine beträchtliche, so lässt sie sich auf sehr hohe Grade dadurch steigern, dass Störungen in der Blutbildung erzengt werden, Quincke ${ }^{1}$ ) erzielte diese verstärkte hämatogene "Siderosis", indem er bei Hunden durch intravenöse Transfusion gleichartigen Blutes Plethora hervorrief. I. Arnold ${ }^{2}$ ) fand eine oft sehr hochgradige "Deposition eisenhaltiger Pigmentes" in den genannten Organer, sowle in den Lungen, Bronchialdrïsen und Nieren bei Hunden und Kaninchen, welche längere Zeit in Staubkammern zugebracht hatten. Die gemeinsame Folge der veränderten Lebensbedingungen in diesen Fällen liegt in dem gesteigerten Untergang rother Blutkörperchen und vermehrter Anhäufung ihrer Umwandlungsproducte in den Geweben. Die Untersuchungen von Tizzoni und Fileti ${ }^{3}$ ) galten hauptsächlich dem Knochenmark, auf welches sie durch Exstirpation der Milz die Functionen derselben übertrugen und die Ablagerung des eisenhaltigen Pigmentes concentrirten. Es ist zweifellos, dass alles unter solchen Verhältnissen in den Organen angesammelte Pigment denselben Entstehungsmodus besitzt. Um so überraschender ist das Ergebniss

1) Quincke, Zur Pathologie des Blutes. Ueber Siderosis. Deutsches Erchiv f. Jin. Med. Bd.XXV u. XXVIT. 1880.

3) J. Arnold, Staubiahalation und Staubmetastase. S. 186 ff. 1886 .

5) Tiztoni e Fileti, Studi patologici e chimici sulla funzione ematopoetica. Atti della r. accademia dei lincei. 1881. 
der Eisenreaction, welche man an Schnitten von Milz, Knochenmark und Leber vornimmt. Ein grosser Theil der Kugeln und Körner nimmt bei Behandlung mit Ferrocyankali und Salzsäure eine gesättigte, tiefblaue Farbe an; man erhält den Eindruck, als sei das ganze Korn in reines Berlinerblau übergeführt. Ein anderer Theil des Pigmentes aber bekommt nur einen bläulichen Schimmer, neben welchem das ursprüngliche Gelb oder Braun noch mehr oder weniger stark vorherrscht, so dass oft ein schmutzig grüner Ton resultirt; und noch andere Körner behalten ihre ursprüngliche Farbe unverändert bei. Diese Verschiedenheiten sind nicht etwa abhängig von der Grösse der Körner, so dass man eine schnellere oder langsamere Einwirkung der Reagentien, oder von der Lagerung, so dass man verschiedene Lebensbedingungen der einzelnen Gewebsbezirke anschuldigen dürfte; grosse und kleine Kugeln, gleichgültig, ob in Zellen eingeschlossen oder frei liegend, ob innerhalb der Gefässbahnen, oder im Gewebe selbst deponirt, unterliegen diesem Wechsel; nicht selten trifft man sogar in einer und derselben Zelle Pigment, welches die Reaction in vollstem Massse giebt, neben solchem, welches sie absolut verweigert. Nur ein Unterschied in der Farbennuance der nicht reagirenden gegenüber den sich bläuenden Köruern ist mir aufgefallen: Meistens, wenn auch nicht durchweg, gehören die ersteren zur Klasse der rotbbraunen. die letzteren $z u$ der der mehr gelben ${ }^{1}$.

Dieselbe Verschiedenheit in der Intensität des Farbenwechsels begegnete mir noch in einer grossen Reihe pathologischer Präparate, welche notorisch hämatogenes Pigment enthielten, weniger deutlich oder gar nicht bei solchen, wo ein Trauma eine einmalige Hämorrhagie hervorgerufen hatte, mit grosser Regelmässigkeit aber in den Fällen, bei denen wiederholter Blutaustritt angenommen werden musste. Ich führe nur einzelne typische Beispiele an: Die Epuliden sind vermöge ihrer Localisation häufigen Traumen ansgesetzt, durch welche Hämorrhagien in ihrem Gewebe entstehen, als deren Residuum körniges goldgelbes und rothbraunes Pigment fast niemals vermisst wird. In 3 Fällen

1) Zur yichtigen Beurtheilung dieser Verhältnisse ist os nöthig, frisch angefertigte Präparate $z x$ studiren, da in älteren die blane Färbung bisweilen wiecter aus eínzelnen Körnern verschwindet. 
von epuliden Riesenzellensarcomen fand ich solches in grosser Menge, bald in den Spindel- oder Riesenzellen, bald neben diesen und vor allem reichlich zwischen den Zellen der überziehenden Schleimhaut. Bei der Eisenreaction traten alle Variationen der Blaufärbung ein und ein Theil der Pigmentkörner blieb vollständig unverändert; derjenige Tumor, in welchem die Differenz in dem Farbenwechsel am ausgeprägtesten war, bestand seit 7 Monaten. Von der braunen Induration der Lunge standen mir 3 Fälle zu Gebote. Das Pigment bei dieser Erkrankung ist hämatogener Natur und unter gleichen Verhältnissen entstanden, das Umwandlungsproduct der in die Alveolarlumina und das Gewebe erfolgten Stauungsblutungen; trotzdem hatte die Eisenreaction sehr ungleichen Erfolg, liess einen Theil der Körner vollständig intact und förderte an den ïbrigen alle denkbaren Nuancen zwischen dem gesättigten Blau und dem schwach grünlichen Farbenton zu Tage.

In den genannten Fällen waren die reagirenden Körner weder durch ihre Grösse noch durch ihre Lagerung vor den reagirenden ausgezeichnet; nur schien es auch hier, als ob die helleren, goldgelben mehr zur Reaction neigten, als die dunkleren, braunrothen. In einem weiteren Präparate jedoch fand ich die Differenz in der Blaufärbung abhängig von der Localisation: Das rechte Ovarium einer 32jährigen Frau enthielt eine ziemlich grosse Zahl von Follikelnarben, fast alle mit hyaliner Umwandlung des centralen Bindegewebsbezirkes; in jedem dieser hyalinen Kerne ebenso wie in dem umgebenden zellreichen Gewebe lag viel Pigment, theils frei, theils an Zellen gebunden, in seiner Lagerung häufig dem Verlaufe der Gefässe folgend, von goldgelber bis rothbrauner Farbe und starkem Glanz. Das Ferrocyankali-Salzsäuregemisch hatte auch hier die manoichfaltigste Wirkung, doch machte sich die Differenz in der Intensität des Farbenwechsels weniger an dem Inhalt eines und desselben Follikels geltend, sondern trat erst sehr deutlich bei der Vergleichung der einzelnen Heerde hervor; in jeder einzelnen Narbe fand sich annähernd der gleiche Grad der Bläunng an allen Körnern; in einer waren dieselben vollständig unverändert.

Das geschilderte verschiedene Verhalten des Pigmentes, das doch augenscheinlich gleichen Ursprungs ist und unter gleichen 
Bedingungen sich entwickelt hat, lüsst Zweifel aufkommen, ob dic Ausbildung der eisenhaltigen körnigen Form wirklich die nothwendige Folge der Einwirkung lebenskräftigen Gewebes auf das extravasirte Blut ist, ob nicht unter denselben Verhältnissen ein gleichgeformtes Pigment entstehen kann, welchem die Eisenreaction fehlt. Diese Frage besitzt deshalb eine gewisse Bedeutung, weil man für die Bestimmung des hämatogenen oder autochthonen Charakter's des körnigen Pigmentes den Ausfall der Eisenreaction als maassgebend betrachtet.

Um die Lebensgeschichte des Hämosiderins zu verfolgen und durch sie Aufschluss zu erhalten, erzeugte ich dasselbe experimentell in einer doppelten Versuchsieihe, einer an Fröschen und einer an Kaninchen angestellten.

Der Jymphsack des Frosches ist die geeignetste Localität, um grössere Blutmengen dem Einfluss des Säftestromes auszusetzen und wurde in dieser Eigenschaft schion mehrfach zum Studium der Metamorphose rother Blutkörperchen benutzt: Rindfleisch') schob Froschblutgerinnsel in denselben ein; Preyer ${ }^{2}$ ) durchstach, nachdem er Eiterung im Lymphsacke hervorgerufen hatte, ein Hautgefäss, so dass rothe und weisse Blutkörperchen sich mengten. Zum gleichen Zwecke experimentirte O. Lange ${ }^{1}$ ) in der Weise, dass or das Blut eines Frosches aus der Aorta in den Lymphsack eines anderen transfundirte und nach verschieden langen Zeiträumen wieder mit der Canüle Proben zur frischen Untersuchung entnahm. Diese letztere Methode versuchte ich für meine Experimente zu verwenden; jedoch erwies sich die Fixirung der Zellen an dem Deckglas durch Autrocknen als ungenügend für die Eisenreaction and die Nachfärbung. Um den eingeführten rothen Blutkörperchen von vornherein ein Bett zu geben, in welchem sie später leicht untersucht und conservirt werden konnten, liess ich Hollundermarkplättchen von $100-150 \mu$ Dicke sich mit dem Herzblut eines Frosches vollsaugen und führte sie dann zu mehreren in den Lymphsack eines anderen Frosches durch eine mediane Haut-

1) Rindfleisch, Histologie des Blutes. Leipzig 1863.

2) Preyer, Ueber amöboide Blutkörperchen. Dieses Archiv Bd. 30. 1864.

3) O. Lange, Ueber die Entstehung der blutisörperhaltigen Zellen etc. Dieses Arehiv Bd. 65. 1875. 
wunde am Rücken ein. Aach den Untersuchungen von J. Arnold ${ }^{1}$ ), welcher die in die Maschen solcher Plättchen eingewanderten Ieukocyten Monate lang fortleben und sich weiter entwickeln sah, durfte ich erwarten, die Schicksale der eingeführten rothen Blutkörperchen für längere Zeit darin verfolgen $z u$ können.

Diese Methode ermöglichte es, an einem und demselben Versuchsthiere die verschiedenen Stufen der Pigmentmetamorphose $z u$ beobachten dadurch, dass die Plättchen eines jeden Frosches in verschieden langen Zeitabständen nach einander durch die ursprüngliche Hautwunde wieder entnommen wurden. Nur für die späteren Stadien entfernte ich sämmtliche Plättchen auf einmal, nachdem ich den Frosch durch Verbluten getödtet hatte, um nicht durch Zerreissung der zu dieser Zeit schon vorhandenen Adhäsionen jedesmal den zuräckbleibenden Plättchen vom neuen Blut zuzuführen.

Die längste Zeit, welche die Plättchen im Lymphsack verblieben, betrug 100 Tage.

Nach der Herausnahme wurden sie theils auf dem hohlen Objecträ̈ger in frisch entleertem Hamor aqueus lebend untersucht, theils gehärtet; um die morphologische Seite der Pigmentumwandlung zu studiren, verwendete ich Müller'sche Flüssigkeit; die Objecte, welche der Eisenreaction unterworfen werden sollten, härtete ich in Alkohol von aufsteigender Concentration, da die Behandlung mit Chromsäure bezw. ihreu Salzen den Eintritt der Reaction erschwert oder sogar vereitelt. Für den Nachweis des Eisens bediente ich mich in der Regel der Perls'schen Berlinerblaureaction ${ }^{2}$ ); mittelst der von Quincke angegebenen Schwefelammoniumbehandlung, welche Schwarzärbung des eisenhaltigen Pigmentes hervorruft, controlirte ich nur die Fälle, in denen diffuse Blaufärbung eingetreten war, zur Entscheidung, ob letztere

1) J. Arnold, Ueber Theilungsvorgänge an den Wanderzellen etc. Arch. f. mikrosk. Anat. Bd. XXX. 1887.

2) Icb benutzte eine 2 procentige Ferrocyankalilösung und setzte zu einem Uhrschälchen derselben einen Tropfen reiner Salzsäure; diese Mischung ruft innerhalb weniger Secunden die Blaufärbung hervor, welche bei nachträglicher Tinction wit Alauncarmin ausgezeichnet scharf zu Tage tritt. 
einer präexistenten diffusen Pigmentirung entspräche, oder erst durch nachträgliche Lösung des Berlinerblan zu Stande gekommen wäre.

Die im Folgenden mitgetheilten Befunde sind einer an 44 Fröschen angestellten. Versuchsreibe entnommen. In den frühesten Stadien stellen sie reguläre Bẹispiele für die an allen Versuchsthieren fast schematisch sich abspielenden Vorgänge dar. Von den die spätesten Perioden repräsentirenden Fällen kann jeder nur für sich selbst sprechen, da hier die Entwickelung nicht mehr einen überall gleichmässigen Verlauf nahm.

$$
\text { 1tägiger Versuch. }
$$

I. Lebendes Object, in Fumor aqueus untersucht.

Frosch 6. In den Maschen des Plättchens finden sicb zahlreiche rothe Blutkörperchen, bäufig in Gruppen zusammenliegend. Die meisten haben unveränderte Gestalt, oder sie sind kreisrund geworden, oft unter gleichzeitiger Verlust ibres Kernes; andere sind von einem Spalt durchsetzt, der sie in zwei noch zusammenhängende Abschnitte zerlegt, oder vollständig zerbrochen; endlich trifft man solche, die einmal oder mebrfach eingeschnürt sind, bisweilen Milzform besitzen. Bei allen diesen ist die ursprüngliche grünliche Farbe erhalten geblieben oder sie hat einen mehr oder weniger stark bervortretenden Stich in's Rothe bekommen. In anderen Fällen ist ein Theil des Stromas entfärbt, besonders häufig halbmondförmige Randpartien. Weiterhin treten ausgesprochen grüne KugeIn ron ungefähr der Grösse eines menschlichen rothen Blutkörperchens mit starkem Glanz auf und ebenso gefärbte kleine Körner, letztere in beträchtlicher Zahl.

Weisse Blutkörperchen sind in grosser Menge im Plättchen entbalten, theils ruhend, tbeils mit geweibähnlichen Fortsätzen in lebhafter Bewegung, von wechselndem Unfang, bald mit deutlichem Ken, bald seheinbar ohne einen solchen, bald sehr blass, bald stark glänzend. Im Allgemeinen scheinen sie mit den rothen Blutkörperchen in keine Berührung getreten zu sein. Einzelne von ihnen, ruhende und mobile, enthalten grüne Körner, welche den beschriebenen freiliegenden vollkommen gleichen, und sich entweder in Protoplasma vertheilen, oder, sich in den ruhenden Zellen an einem Pole angebäuft haben; dieselben Körnchen treten neben den grösseren, wie Tropfen erscheinenden grünen Kugeln bisweilen in unregelmässig gestalteten, platten, sehr blassen Zellen mit homogenem Proroplaswa und bald sichtbarem, bald undeutlichem Kern auf.

Frosch 32. Das Plättchen zeigt dieselben Verhältnisse, wie im vorigen Falle, nur fehlt der röthliche Farbenton der Blutscheiben. Ausserdem finden sich viele der letzteren mit deutlichem Kern und scharf contourirtem, aber vollständig farblosem Stroma; ferner viele total abgeschnüte Stäcke rother Blutkörperchen von versehiedener Grösse, kreisrunder Form, grünlieber Farbe 
und mattem Glanz; sie gebeu sich als scheibenformig dadurch zu erkenucu, dass sie darunterliegende föper klar durchscheinen lassen. Mit vielen der rothen Blutkörperchen stehen Leukocyten in Berührung, mit ihren Armen dieseiben umklammend.

II. Gehärtetes Object; Müller'sche Flüssigkeit.

Frosch 32. Gestait und Anordnung der rothen Blutkörperchen und ilirer Bruch - und Schnürstücke gleicht der in lebenden Präparat. Bei der Färbung verhalten sie sich sehr verschieden: Die meisten zeigen einen unveränderten, intensiv färbbaren Kern; das Stroma nimmt bei vielen, besonders den in der Form wohlerhaltenen, durch Eosinbehandlung einen schöuen rosa Ton an; bicht selten jedocb bleiben einzelne Stellen dabei weiss, bald die Gegend eines Poles, bald balbmondförmige Randbezirke, bald unregelmässige Partien inmitten des Stromas; bisweilen wird das letztere überbaupt nicht gefärt,t. Bei anderen wird es mattbraun; noch andere rothe Blutkörperchen besitzen ein durch Eosin nicht veränderliches strohgelbes Stroma. In manchen Fällen endlich ist die Zelle nur durch die scharfen Contouren von Kern und Stroma markirt, aber vollständig tinetionsunfähig. Dieselben Variationen finden sich wieder an den abgebrocbenen und abgeschnürten Theilen der Blutscheiben, mögen sie noch durch schmale Brücken mit diesen verbunden, oder vollständig losgetrennt sein; auch sie schliessen nicht selten farblose Bezirke ein. Ausserdem kommen, durch ihre dunkle Eosinfärbung und ihren stärkeren Glanz von diesen letzteren Formen deutlich unterschieden, runde, kuglige Gebilde von gleicher Grösse nnd neben diesen zah]reiche kleine Kügelchen vor, die letzteren bäufig in Gruppen zusammenliegend, die offenbar mit den im lebenden object beabachteten grünen Tropfen und Kügelchen identisch sind. Leukocyten sind sehr reichlich vertreten, meist rund, mit einew oder mehreren Kernen und bald mehr homogenem, bald fein- oder grobgranulirtem Protoplasma. Viele derselben schliessen einzelne oder zahlreiche der eben beschriebenen kugligen eosingefärbten Gebilde ein.

\section{2 tägiger Versuch.}

I. Lebendes Object, in Humor aqueus untersucht.

Frosch 34. In den Naschen des Plättchens liegen viele rothe Blutkörperchen, theils intact, theils in denselben Stadien der Form- und Farbenveränderung, wie in den 1 Tag alten Präparaten; nur ist der rotbbraune Ton vieler Zellen noch intensiver; bisweilen findet sich das Hämoglobin zu kleinen grünen Kugeln innerhalb des sonst farblosen Stromas zerkJüftet. Abgeschnürte scheiben- und keulenförmige Stücke mit mattem Glanz und röthlichgrüner Farbe sind zablreich vertreten. Ferner trifft uan sehr viele kleine grüne Tröpfchen und grössere Kugeln in mässiger Menge, theils frei, theils im Inueren von Leukocyten, welche letztere in grosser Zabl anftreten, mit mehr oder weniger deutlichem Kern, bald ruhend, rund oder in lange Fäden ausgezogen, baid in lebhafter amöboider Bewegung. Von Pigment ist nichts zu selien. 
II. Gehärtetes Object. Müller'sche Flüssigkeit. Celloidin. Serienschnitte.

Frosch 34. Das Plättchen wird allseitig umbüllt von einem ziemlich dünnen Thrombus, der aus homogenei, hyaliner Substanz besteht, die von spärlichen, meist epithelioiden Zellen durchsetzt ist und bier and da unveränderte rothe Blutkörperchen einschliesst. Der Inbalt der Maschen des Plättchens ist gering; er setzt sich zusammen aus rothen Bluthörperchen, welche, in Form, Farbe und Färbbarkeit denen des 1 Tag alten Präparates gleichend, bald vereinzelt, bald in Gruppen liegen; aus Wanderzellen von runder oder unregelmässiger Gestalt, mit einem oder mehreren Kernen; endlich aus ziemlich spärlich vertretenen, kleineren und grösseren, glänzenden, stärker eosingefäroten Kugeln, welche zum Theil frei, zum Theil im Protoplasma von Leukacyten liegen.

\section{3 tägiger Versuch.}

I. Lebendes Object.

Froseh 6. Nur wenige der rothen Blutkörperchen sind unverändert; die meisten haben den röthlichbraunen Farbenton bekowmen, viele zugleieh durch Abrundung, Faltung, Zerbrecben oder Abscbnürung andere Gestait argenommen. Der Vorgang der Zerschnürung spielte sich einmal unter den Augen ab: Ein bohnenförmiges rothes Blutkörperchen trägt anf einem dem Pol aufsitzenden Stiel eine Knospe; an der Stiel liegt ein Leukocyt, welcher sich lebhaft bewegt und seine Arme längs der beiden Abschnitte der Zelle hingleiten lässt; nach $\frac{1}{4}$ stündiger Beobachtung ist der allmählich dünner gewordene Stiel vollständig geschwunden und ein kreisrundes, plattes, kernloses Gebilde von der gleichen Farbe und dem gleichen matten Glanz, wie die Mutterzelle, losgetrennt. - In ziemlich bedeutender Zahl trifft man grüne glänzende Kügelchen und Tropfen. Die Zertheilung eines solchen von ungefähr der Grösse eines menschlichen rothen Blutkörperchens in eine Gruppe der kleinen Kugeln hatte ich einmal Gelegenheit zu beobachten: Derselbe lag in unmittelbarer Nähe mehrerer in amöboider Bewogung begriffener Teukocyten; einer von diesen umfasste ihn mit einem Arw und zog ihn heran; während dieses Actes schossen plötzlich auf der bisher vollständig glatten Oberfläche eine Menge kleiner glänzender Prominënzen bervor, so dass die bisherige Kugel die granulirte Gestalt einer Naulbeere annahm. Eine Erschütterung des Präparates, offenbar durch Verdunstungsvorgänge aw Rande bedingt, ertheilte allen Zellen einen plötzlichen Stoss, bei welchem der Tropfen, wie es schien, mit einem Theil des umschlingenden Protoplasmaarmes von seinem Träger losgerissen wurde. Wenig später umfasste ibn ein anderer Leukocyt, die Granulirung nahm zu, und endlich löste sich die Beere in eine Zabl kleiner grüner Kügelchen auf, welche sich im umgebenden Protoplasma vertheilten. Zellen mit derartigem Inhalt, bald ruhend, bald mobil, sind ziemlich reichlich vertreten. Nicht selten aber machen sich ar den eingeschlossenen Körnchen Farbennüancen bemerkbar, welche in den früheren Tagen fehlten: Bei einigen ist ein gelber Ton aufgetreten, bis-

Archiv f, pathol. Anat. Bd. 115. Hot. 3 . 
weilen nur als discreter Anflug, welcher das ursprüngliche Grïn richt verdeckt; andere Male aber prävalirt er vor diesem und schliesslich ersetzt er es sogar ganz und verleiht dem Korn ein rein goldgelbes oder gelbbraunes Aussehen. Diese letzteren Gebilde verdienen mit vollem Recht die Bezeichnung als Pigmentkörner. Oft finden sich das unveränderte Grün und die verschiedenen Grade dor Gelbfärbung neben einander am Inbalt einer und derselben Zelle oder an den Elementen einer freiliegenden Körnchengruppe. Seltener besitzen die Pigmentpartikel grösseren Umfang und dann in der Regel unregelmässig eckige Gestalt.

II. Gehärtetes Object. Mäler'sche Elüssigkeit.

Frosch 32, Gas Plättchen enthält viele weisse Blutkörperchen mit einem oder mehreren Kernen der verschiedensten Gestalt; ihr. Protoplasma ist bald howogen, bald gekörnt, vor Allem reichlich sind Zellen mit sehr grobgranuJirtem eosinopbylen Protoplasma. Vide dieser Leulocyten schliessen Kugeln ein von wechselndem Umfang, von den ungefähr einem menschlichen rothen Blutkörperchen gleichkommenden an in abnehmender Grösse bis zu kleinen Körnchen herab. Dieselben besitzen lebhaften Glanz, dunklen Contour und sind zum Theil durch Eosin rosa tingirt, zum Theil aber unbeeinflusst von der Eosiubehandlung geblieben, von reiner goldgelber oder gelbbrauner Farbe, vollkommen dem Pigment im lebenden Object gleichend. Bald liegt nur eines dieser Gebilde in einer Zelle, bald mehrore, den versehiedensten Grössenformen angehörige zugleich, eosingefürbte mit braunen Pigwentiörnern gemischt. Ebensolche Kugeln und Kügelchen trifft man bäufig frei, bald isolirt, bald zu Gruppen geordnet. Die sehr zablreicben rothen Blutkörperchen sind fast sämmtlich nach Form, Farbe und Färbbarkeit in derselben Weise verändert, wie in den Präparaten der früheren Tage.

$$
4 \text { tägiger Versuch. }
$$

Lebendes object.

Frosch 6. Die Pigmentbildung hat seit gestern bedeutend zugenommen; die Körner, von meist braungelber Farbe und wechselndem Umfang, liegen ausschliesslich im Innern von Leukocyten, bald nur vereinzelt, bald zu vielen in einer Zelle; im letzteren Falle formiren sie nicht selten maubeerähnliche Gruppen. Die stärkst pigmentirten Zellen sind meist etwas nufangreicher; liegen zum grössten Theil rubig, zum kleineren fübren sie amöboide Bewegungen aus. In vielen von ihnen trifft man ausserdem einzelne noch grüne, glänzende Kügelchen. Im Uebrigen finden sich dieselben Zeliformen, wie gestern.

7 tägiger Versuch.

I. Lebendes Object.

Frosch 37. Neben mehr oder weniger veränderten rotben Blutḳöperchen trifft man noch ziemlich viel vollkommen intacte. Die Wanderzellen sind sehr reichlich; viele schliessen neben Pigmentkörnchen noch rein grüne Kägelchen, oder solche mit einem Sticb in's Gelbbraune ein.

Frosch 18. Neben den eben beschriebenen Zellen finden sich nicht 
selten sehr grosse, zum Theil in amöboider Bewegung begriffene, welche fast ganz erfüllt sind von grüngelben, etwas schmutzig erscheinenden Schollen. Freies Pigment ist nirgends zn sehen.

II. Gehärtetes Object.

Frosch 38. Plättchen der Haut adhärent, mit dieser in Müller'scher Flüssigkeit gehärtet; Celloidineinbettung, Serienschnitte. - Das Plättchen wird umhällt von einem Thrombus, der etwas dünner, als dieses selbst, circa $120 \mu$ dick ist. Derselbe besteht ans hyaliner Substanz und ist in senkrechter Richtung von zablreichen verzweigten. Spalten durchsetzt, innerhalb derer sich Wanderzellen, besonders solche mit grobgranulirtem, eosinophilem Protoplasma aufhalten, am reichlichsten in den tiefsten Schichten. Vereinzelt finden sich in ihw Nester unveränderter rother Blutkörperchen eingeschlossen. Die Maschen des Plättchens enthalten mässig viele Zellen, theils grössere mit epithelioidem Charakter, theils kleine mit vielgestaltigen Kernen. Pigment ist in ziemlich spärlicher Menge vorhanden in Form runder oder eckiger glänzender gelbbrauner Körner.

Frosch 37. Das Plättchen ist von der Haut und der Röckenmusculatur durch Thrombusschichten getrennt, aus welchen es sich Jeicht ausschälen lässt; es wird in toto in Alkohol gebärtet und der Lisenreaction unterworfen. In seinen Maschen liegt viel körniges Pigment, theils frei, theils in Wanderzellen eingeschlossen, welches von der Reaction vollständig unberührt geblieben ist.

\section{3 tägiger Versuch.}

Frosch 33. Ein Plättchen wird mit dem umgebenden Thrombus der Eisenreaction unterworfen. Der reichliche Inbalt der Maschen setzt sich zulsammen aus Zellen, welche meist grosse, bläschenförmige, helle, seltener kleine vielgestaltige Kerne besitzen; ziemlich häufig sind vielkernige Riesenzellen. Mit Vorliebe in den Septenwinkeln liegen Gruppen rother Blutkörperchen, meist mit wohlerhaltenem Kern, mit nngefübtem oder gelbliehem Stroma, welches durch Eosinbehandlung unbeeinflusst bleibt, wit mebr oder weniger veränderter Gestalt. Das Pigment der Plättchenmaschen ist ziem. lich spärlich, theils in Zellen eingeschlossen, theils freiliegend; ibrer Farbe nach gleichen die Körner vollkommen den beim vorigen Versuch beschriebenen; die Eisenreaction ist durchweg erfolglos geblieben. Der umbüllende Thrombus Jässt sich als zusammenhängendes Häutchen abzieben. Er setzt sich zusammen aus zahlreichen Zellen, unter welchen die grossen mit bläschenförmigen Kernen prävaliren, und einer homogenen hyalinen Zwischensubstanz; auf der dem Plättchen zugekebrt gewesenen Fläche ziehen vielfach lange Fäden, die sich häufig durchflechten und langgestreckte Kerne einschliessen; auch rothe Blutkörperchen trifft man noch hier und da im Thrombus. Das Pigment ist in ihm reichlich vertreten, z. Th. in den dem Plättchen zunächst gelegenen Schichten, oder an der Grenze von ihm und dew Plättchen. Ein Theil wird von Zellen umschlossen, ein ebenso grosser liegt neben diesen, bald in mehr oder weniger dichtstehenden Heerden, bald 
in Form verstreuter Körnchen. An Umfang erreichen einige Körner ein menschliches rothes Blutkörperchen, oder übertreffen es sogar, indessen überwiegen die kleineren Sorten. An keinem der Pigmentpartikel ist die geringste Spur der Wirkng der Eisenreaction zu bemerken, alle behalten ibre gelbbraune Farbe unverändert bei.

Ein der Haut adhärentes Plättchen wird mit dieser eingebettet; Serienschnitte. Der das Plättchen allseitig unhüllende Thrombus besitzt ungefähr dieselbe Dicke, wie dieses, $100 "$; er besteht aus hyaliner Substanz und beberbergt in den verzweigten Spalten, besonders reichlich in den tiefsten Schichten, Zellen verschiedener Form. In der Nähe des Plättchens, bisweilen demselben direct anfliegend, mit Vorliebe dem Rande entsprechend, sind rothe Blutkörperchen eingesehlossen, selten einzeln, meist zu fächenhaft ausgebreiteten Blutthromben rereinigt; die einzelnen haben meist, abgesehen von der gegenseitigen Abplattung, ihre ursprüngliche Form beibebalten; ihr strobgelbes Stroma wird bei Eosinbehandlung nur etwas dunkler, ohne den Grundton zu verlieren. Gefässe sind in Thrombus nicht vorbanden. Der Inhalt der Maschen des Plättchens besteht aus rothen Blutkörperchen, die in Form und Farbe mehr oder weniger verändert in den Septenwinkeln liegen, aus epithelioiden Zellen und kleiuen mit polymorphen Kernen; hier und da trifft man Spuren zerfallener Zellen. Im Thrombus, wie im Plättehen liegt körniges Pigment, fast ansschliesslich von Wanderzellen eingeschlossen; gegen die Eisenreaction verhält es sich durchweg ablehnend. Wohl aber gehen bei Anwendung derselben einzelne Abschnitte der erwähnten Blutthromben einen Farbenwechsel ein dadurch, dass kernhaltige rothe Blutkörperchen, obwohl durch nichts von ihren nicht reagirenden Nachbarn ausgezeichnet, äber das ganze Stroma oder nur einen Thei! dosselben himmelblaue Farbe annehmen.

\section{0 tägiger Versuch.}

Frosch 4t. Plättchen mit der llaut in Alkohol gehärtet. Celloidin; Serienschnitte. - Der das Plättchen allseitig unhällende, nach aussen mit der Haut verklebte Thrombus ist sehr dick. Er besteht aus hyaliner Substanz und schliesst in den mittleren Schichten spärliche, in den inneren und änsseren reichliche Zellen ein, theils grössere mit bläschenförmigen, theils kleinere mit vielgestaltigen Kemen; ausserdem enthält er noch unveränderte rothe Blutkörperchen, bisweilen in kleinen Gruppen, bisweilen, besonders an den Rändern des Plättchens, in ausgedehnteren Heerden. Nirgends trifft man Gefässe im Thrombus. Der reichliche Inbait der Maschen des Plätchens setat sich zusammen aus denselben Elementen, welche sich im Thrombus fanden, ohne dass die eine oder andere Zellform prävalirte; nicht selten bilden sie auf den Septen der Alveolen einen continuirlichen platten Belag; hier und da liegen Spuren zerfallener oder degenerirter Zellen. Von den rothen Blutkörperchen trifft man Gruppen in den Septenwinkeln in reichlicher Menge; spärlicher sind ihre Umwandlungsproducte in Form körnigen, goldgelben, glänzenten Pigments, welches dem Thrombus und dem Plättchen, 
Jetzterem in überwiegender Nenge, angehört: die Körner sind rund ader eckig, von wechselndem Umfang, die grössten erreichen kaum den eines menschlichen rothen Blutkörperchens. Bald treten sie frei auf, isolirt, oder , zu Gruppen geordnet, bald in Leukocyten eingeschlossen, meist zu mehreren, die verschiedensten Grössenformen repräsentirenden, in derselben Zelle.

Bei der Eisenreaction bleiben sämmtliche Körner unverändert.

28 tägiger Versuch.

Frosch 41. Plättchen mit Haut. Alkobol. Celloidin. Serienschnitte. Der mit der Haut verklebte Thrombus ist wenig dünner, als das cirea $150 \mu$ dicke Plättchen. Seine hyaline, zerklüftete Substanz enthält nur in den dem Plättchen näheren Schichten reichlichere Zellen, theils unverändert leukocytären, theils epithelioiden Charakters; anch hier finden sich noch zahlreiche rothe Blutkörperchen, bisweilen zu flächenhaften Heerden angeordnet. Von Vascularisation ist nirgends etwas zu sehen. In den Naschen des Plättchens liegen dieselben zelligen Elemente, wie beim vorigen Versuch, ausserdem ziemlich zahlreiche Riesenzellen mit vielen grossen Kernen. Plättchen und Thrombus, ersteres in reichlicherer Menge, enthalten gelbbraune, glänzende Pigmentkörner von runder oder unregelmässig eckiger Gestalt, welche ebenso oft in den verschiedenartigen Zellen, als neben ibnen liegen.

Keines der Körner gelt bei Anwendung der Eisenreaction den Farbenwechsel ein.

\section{6 tägiger Versueh.}

Froseh 43. Plättchen mit Haut; Bebandlung wie im vorigen Versuch. - Der Lymphthrombus, von mittlerer Dicke, enthält vorwiegend epitheloide Zellen; die kleineren mit vielgestaltigen Kernen sind spärlich. In den tieferen Schichten nähern sich die grösseren bisweilen der Spindelform. Gefässe feblen vollständig. In den Maschen des Plättchens ist das Verhältniss der unveränderten kleinen Wanderzellen zu denen mit grossen hellen Kernen ungefäbr das gleiche, wie im Thrombus; vielfach tragen die Septen einen endothelartigen Belag; hier und da liegen vielkernige Riesenzellen. Das Pigment ist ziemlich sparsam vertreten; der Haupttheil gebört dem Plättchen selbst an, der kleinere den tiefen Thrombusschichten. In Form und Grösse, sowie in ihrer Beziehung zu den Zellen verhalten sich die Körner wie im letztbeschriebenen Präparat.

Die Eisenreaction bat überall negatives Resultat.

$$
46 \text { tägiger Versucb. }
$$

Frosch 27. Eines der Plättchen wird mit der Haut zusammen eingebettet und gescbnitten. - Der Thrombus, von ungefähr derselben Dicke, wie das Plättchen, circa 150 ", besteht in den äusseren Lagen aus der Oberfläche parallel geschichteten langen Spindelzellen, in den tieferen aus unregelmässig angeordneten epitheloiden Zellen; alle Schicbten enthalten in ziemlicher Menge kleine Leukocyten mit grobgranulirtem, eosinophilem Protoplasma. Ein äbuliches Gewebe füllt die äusseren Plättchenmaschen, nur sind hier die 
unveränderten Wanderzellen seltener und als neue Elemente treten hier. und da Riesenzellen hinzu; in den inneren Maschen trifft man vielfach auf Erscheinungen von Degeneration und Zerfall der Zellen. In den Septenwinkeln und bisweilen auch im Thrombus finden sich wohlerhaltene rothe Blutkörperchen, meist zu Gruppen vereinigt. Im Thrombus verlaufen reichlicbe weite Gefässe, welche vielfach bis zur Grenze des Plättchens reichen; ein Eindringen in die Maschen des letzteren jedoch ist nirgends zu erkennen; ein quantitativer Unterschied in der Vascularisation der beiden Hälften des Throwbus scheint nicht zu besteben. Hauptsächlich an der Grenze zwischen Thrombus und Plättchen, in geringerer Menge auch in den Mascben des ersteren und in der tieferen Schicht des letzteren liegt Pigment in ziemlicher Henge, durchweg körniger Natur; die Farbe und Grösse der Körner ist die gleiche, wie in den letzten Versuchen, die kleineren Formen prävaliren; die äberwiegende Zahl füllt das Protoplasma der Zellen, relativ wenige Körner liegen frei. Das Ferrocyankali-Salzsäuregemisch wirkt auf dieselben verschieden ein: In der zwischen Haut und Plättchen befindlichen Throrobushälfte geht fast das ganze Pigment den Farbenwechsel ein und nimmt ein tiefes, gesättigtes Blau an, nur ein geringer Theil bleibt unverändert; in der zwischen Plättchen und Rückenmusculatur liegenden Hälfte ist das Verhältniss umgekehrt, nur wenige Körner bläuen sich, die meisten widerstehen der Reaction. Das in den Maschen selbst gelegene Pigwent ist durcbweg unemptänglich für dieselbe.

Zwei weitere Plättchen werden in toto mit den umbüllenden Thromben der Reaction unterworfen. - Der sehr zellreiche Thrombus ist von vielen Gefässen durchzogen; neben reichlichen glänzenden Pigmentkörnern von gelbbrauner und braunrother Farbe, welche keine Spuren der Reaction erkenren lassen, finden sich, oft mit diesen in dieselben Zellen eingeschlossen, Gebilde von gleicher Grösse und Gestalt und gesättigt tiefblauer Farbe; dieselben gehören besonders den dem Plättchen zunächst gelegenen Schichten an. In den Maschen des Plättchens liegt viel Pigment, welches durchweg seine gelboder rothbratne Farbe bewabrt hat.

Frosch 26. Ein Plättchen mit seinem Thrombus in toto der Reaction unterworfen. - Der Thrombus zeigt dieselben Verbältnisse, wie im letztbescbriebenen Falle; die Menge der blauen Körner ist ungefäbr gleich der der unveränilert gebliebenen. Die Maschen des Plättchens enthalten kein Pigment.

56 tägiger Versuch.

Frosch 28. Plättchen mit Haut; Celloidin; Serienschnitte. - Das Plättchen ist allseitig umschlossen von einem Thrombus, dessen oberes, der Haut seite aufliegendes Blatt seine circa 120 " betragende Dicke übertrifft, dessen unteres dieselbe nicht ganz erreicht. Der Thrombus enthält in den äusseren Schichten parallel gelagerte, spindelförmige, in den tieferen dichtstehende Zellen von mehr epithelioidem Charakter in regelloser Anordnung, und da$z$ wischen wenig kleine Zellen mit polymorphen Kernen; mehrfach liegen in ihm noch untegelmässig gestaltete Heerde rother Blutkörperchen ohne scharfe 
Begrenzıng und ohne Wandung; die rothen Blutkörperchen selbst besitzen meist färbbare Kerne und strohgelbes, von Eosin nicht verändertes Stroma. Im Thrombus vellaufen sehr viele weite Gefässe, die am reichlichsten in den äusseren Schichten sind, indessen vielfach auch in den inneren bis zur Grenze des Plättchens vordringen und bier and da sich sogar in die oberfächlichsten Maschen einsenken. In der zwischen Plättehen und Haut befindlichen Hälfte ist die Vascularisation stärker, als in der der Rückenunseulatur zugekehrten. In den Maschen des Plättchens liegen viele Zellen, meist epithelioiden Charakters, dazwischen spärliche kleine mit vielgestaltigen Kernen und vereinzelte Riesenzellen; an manchen Stellen finden sich Zeichen von Zelldegeneration; auch hier kommen noch Gruppen wenig veränderter rother Blutkörperehen vor. Der Thrombus und das Plättchen enthalten eine mässige Menge gelb - und rothbrauner, glänzender Pigmentkörnchen ron mittlerem und kleinem Umfang; dieselben liegen bald frei, bald in Zellen, im ersteren Falle meist verstreut, seltener zu Gruppen geordnet.

Bei der Eisenreaction bleibt ein Theil des Pigmentes vollständig unverandert, ein ungefähr eben so grosser Theil aber nimmt eine gesättigte, tiefblaue Farbe an, die reagirenden Körner gehören ausschliesslich dem Thrombus an, und zwar ist ihre relative Menge gegenüber den unempfänglichen geringer in den tieferen, als in den oberflächlichen Schichten. Das im Plättchen selbst liegende Pigment verweigert durchweg die Reaction.

Drei weitere Plättchen desselben Frosches bieten dieselben Verhältnisse dar.

\section{6ótägiger Versuch.}

Frosch 29. Plättchen mit Haut; Celloidin; Serienschnitte. - Der Thrombus besitzt annähernd die gleiche Dicke, wie das Plättchen, circa $120 \ldots . \mathrm{Er}$ und die Gewebspfröpfe in den Plättchenmaschen verhalten sicb bezüglich ihrer Zusammensetzung wie im vorigen Versuch. In seiner unteren Hälfte finden sich keine Blutgefässe, in die obere dringen von der Haut aus ganz vereinzelte ein, reichen aber nirgends über die nittleren Sehichten hinaus. Die Jaschen des Plättchens enthalten viel goldgelbes bis rotbbraunes, glänzendes Pigment, das Thrombusgewebe nur spärliche Mengen. Die Körner, unter denen die kleinen Formen vorherrsehen, liegen bald frei, bald an Zellen gebunden.

Die Eisenreaction ist wenig ergiebig: Fast das ganze Pigment bleibt unverändert, nur ganz vereinzelte Körnchen werden blau.

Zwei weitere Plättchen desselben Frosches, welche den Rückenmuskeln lose anhaften, werden mit diesen im Zusammenhang eingebettet und geschnitten. Die Thromben, etwas dünner, als die etwa $150 \mu$ dicken Plättchen, sind reicher an Zellen als im eben beschriebenen Falle, die meist epitbelioides Ausseben haben, obne regelmässige Anordnung; der Inhalt der Maschen unterscheidet sich rom vorigen Plättchen durch das Vorhandensein sehr zahlreicher kreisrunder oder keulenförmiger Schnürstücke rother Blutkörperchen von schmutzig-gelber Farbe. In bedlen Thromben ist von Ge- 
füssen nichts zu seben. Das Pigment ist im Plättchen reichlich, im Thrombus spärlicher. Bei Anwendung der Eisenreaction bleibt es vollständig unverändert.

\section{0 tägiger Versuch.}

Frosch 30. PJättchen mit Haut; Celloidin; Serienschnitte. -- Der Tbrombus, welcher der Haut nur an wenig circumscripten Stellen adbärirt, übertrifft an Dicke das Plättchen, in seinen äusseren Schichten besteht er aus parallel verlaufenden Spindelzellen, in den inneren aus epithelioiden, zwischen denen sich ziemlich zahlreiche kleine Wanderzellen mit grobgranulirtem, eosinophilem Protoplasma aufbalten. Der Thrombus ist vascularisirt, jedoch gehören die Gefässe nur den oberflächlichen Schichten an. Die Maschen enthalten dieselben zelligen Elemente, wie im letzten Versuch. Von dem ziemlich reichlichen, im Thrombus wie im Plättchen liegenden Pigment geht bei der Eisenreaction kein einziges Körnchen den Farbenwechsel ein.

$$
100 \text { tägiger Versuch. }
$$

Frosch 31. Die drei Plättchen liegen fast lose im Lymphsack, sind nur durch ganz wenige Fädchen mit der Hant oder der Rückenmusculatur verwachsen. Celloidin; Serienschnitte. - Alle 3 Plättchen zeigen dieselben Verhältnisse. Der umbüllende Thrombus, von circa $100, \mu$ Dicke, besteht vorwiegend aus spindelförmigen Zellen, die der Oberfläche parallel geschichtet sind; nur seine tiefsten Lagen sind aus epithelioiden, keulenförmigen, bisweilen cylindrischen Zellen zusammengesetzt. Dieselben Elemente machen auch den Inbalt der Plättchenmaschen aus; zwischen ihnen liegen hier und da Riesenzellen. $\mathrm{Ab}$ und $\mathrm{zu}$ trifft man zu Gruppen vereinigte rothe Plutkörperchen, mit Vorliebe in den Septenwinkeln. Wie nach den geringen Verwachsungen mit der Umgebung zu erwarten war, ist die Vascularisation der Thromben eine äusserst dürftige; in dem des einen. Plättchens fand ich überhaupt keine Gefässe, in denen der beiden anderen nur vereinzelte, welche nicht über die äusseren Schichten hinausdringen. In den Maschen wie in den Thromben liegt ziemlich viel Pigment in Form runder und eckiger, glänzender Körner von gelbbrauner Farbe, deren Grösse innerhalb derselben Grenzen schwankt, wie in den früheren Versuchen; freie und in Zellen eingeschiossene trifft man ungefähr in gleicher Menge.

Bei der Eisenreaction tritt an keinem einzigen Körnchen Farbenwechsel ein.

In den mitgetheilten Beobachtungen sind die an überlebenden Plättchen gemachten nicht eingeschlossen worden. Oft liess ich, nachdem die Wanderzellen in die Maschen eingedrungen waren, den Prozess anstatt im Lymphsack über dem ausgeschliffenen Objectträger in Humor aquens sich weiter abspielen, um an einer und derselben Zelle die Fortschritte der Pigmentmetamorphose zu verfolgen. Es gelang mir, solche Plättchen 
bis zu 4 Tagen in maximo nach der Entnahme aus dem Lymphsack lebend aufzubewahren. Jedoch hielt die Entwickelung des Prozesses innerhalb dieser Kammern nicht gleichen Schritt mit der im Lymphsack selbst. Die Zellen lebten und bewegten sich, die eingeschlossenen grossen Hämoglobintropfen wurden zerkleinert, einzelne der kleinen Kägelchen bräunten sich, aber im Ganzen schienen die Lebensvorgänge nur die ersten Stunden über mit voller Intensität sich fortzasetzen; ich erkannte in den folgenden Tagen nur an wenigen Zellen geringe Fortschritte, die meisten Zellen behielten ihr ursprüngliches Aussehen bei.

Die Veränderungen, welche die in den Lymphsack eingelegten Plättchen, abgesehen von ihrem miteingeführten Inhalt erfuhren, sind die gleichen, welche J. Arnold geschildert hat. Sehr bald nach der Einführung wandern Leukocyten der verschiedenen Formen and Grössen ein und verwandeln sich hier unter Vermehrung in epitheloide, spindelige und Riesenzellen. Das ganze Plättchen wird schon vom zweiten Tage an von feinen Häutchen umhüllt; anfangs bleiben dieselben bei der Eröfinung des Lymphsackes leicht an der Haut und der Rückenmusculatur hängen, so dass sich das Plättchen aus ihnen ausschält; später umschliessen sie unter gleichzeitiger Dickenzunahme dasselbe fester und bleiben mit ihm in Zusammenhang, wobei die Aussenseite mit der Haut oder den Rückenmuskeln bald nur an wenig Punkten, bald auf grössere Strecken hin verklebt. Histologisch besteht der Thrombus zuerst aus gleichmässig hyaliner Masse, die sich zerklüftet und von verzweigten Spalten durchsetzt wird und allmählich Leukocyten in sich aufnimmt, welche dieselben Metamorphosen, wie die im Plättchen selbst befindlichen durchmachen. So entsteht schliesslich ein dickes zellreiches Gewebe mit allmählich immer mehr abnehmender Intercellularsubstanz, welches das Plättchen allseitig umhüllt und seinen Inhalt gegen die Umgebung fest abschliesst. In diese Gewebshülle dringen dann Gefässe ein, jedoch unterliegt die Zeit, in welcher die Vascularisation beginnt und der Grad derselben grossen Schwankungen: das Auftreten einzelner Gefässe beobachtete ich zuerst an den Thromben der 46 Tage alten Plättchen; hier reichten sie bis zur Oberfläche des Plättchens, ohne jedoch in dasselbe einzudringen; an dem vom 65 . Tag stammen- 
den Objecte war nur eine äusserst spärliche und auf die oberflächlichsten Schichten des Thrombus beschränkte Vascularisirung zu bemerken; ebenso fehlte sie fast vollständig in den 70 und 100 Tage alten Präparaten.

Die ersten Unwandlungen, welche sich an den eingeführten rothen Blutkörperchen vollziehen, sind Veränderungen ihrer Form und Farbe. In beiden Beziehungen fand ich meine Beobachtungen in vollkommener Uebereinstimmung mit den Bildern, welche J. Arnold ${ }^{1}$ ) erhielt, nachdem er an der Froschzunge durch Umschnürung der Vena mediana Diapedese rother Blutkörperchen hervorgerufen hatte. Die Veräuderungen der Form bestehen in dem Uebergang der elliptischen Gebilde in kreisrunde Scheiben unter Beibehaltung des Gesammtrolumens, oder es tritt eine Zertrümmerung ein, welche zur Bildung von kernhaltigen und kernlosen Bruchstücken führt, die an einer Seite von einer.geradlinigen Kante begrenzt werden; diese Spaltung beruht ebenso, wie die häufig $z u$ beobachtende Faltung auf rein mechanischen Momenten, darauf, dass die Zellen durch Anstossen an die Septen des Hollundermarkplättchens oder an benachbarte zellige Gebilde zerbrochen werden. Eine zweite Art der Zertheilung ist die Abschnïrung, bei welcher an den Rändern Einkerbungen auftreten, welche durch allmähliche Vertiefung zur Bildung einer Knospe führen, die anfangs noch durch einen Stiel mit dem Mutterkörper verbunden, schliesslich ganz von diesem losgetrennt wird. Dieser Prozess ist nicht ein activer, durch amöboide Bewegungsfähigkeit des rothen Blutkörperchens selbst bedingter, wie Preyer ${ }^{2}$ ) annimmt, sondern er entwickelt sich unter dem Einfluss von Leukocyten. Hat man Gelegenheit, seine Entwickelung unter dem Mikroskop zu verfolgen, so bemerkt man, wie ein Leukocyt sich zuerst an den Rand der Scheibe anlegt, einen Arm ausschickt, welcher dieselbe umfängt und unter fortwährender Bewegung die Abschnürung vollzieht. Dass diese Thätigkeit hänfig genug vor ihrer Vollendung unterbrochen wird, lehren die Befunde von rothen Blutkörperchen, welche gestielte Anhängsel tragen, ohne dass eine amöboide Zelle an ihnen haftet; solche Gebilde zeigen auch nach stundenlanger Beobachtung keinen

1) J. Arnold, Ueber Diapedesis. Dieses Archiv Bd. 58. 1873.

2) Preyer, Ceber amöboide Blutkörperchen. Dieses Archiv Bd.30. 1864. 
Fortschritt in der Abschnürung. Die losgetrennten Stücke sind meist scheibenförmige Körper von derselben gelbgrünlichen Farbe und dem gleichen matten Glanz, wie ihre Mutterzelle.

Diese Formveränderungen spielen für die folgende Pigmentbildung keine wichtige Rolle. Eine um so grössere Bedeutung für diese hat die Wandelung der Färbung der rothen Blutkörperchen. Die Einleitung für den ganzen Pigmentprozess bildet das Verschwinden des Hämoglobins aus denselben. Ich sah auch dieses nach denselben Typen sich vollziehen, welche J. Arnold nach seinen erwähnten Experimenten an der Froschzunge aufstellt, und fand die einzelnen Phasen des Vorganges im gehärteten Präparat wieder: Bald lichtet sich eine Stelle der Peripherie und vergrössert sich allmählich nach dem Centrum zu, bald mehrere gleichzeitig, bald entsteht im ganzen Umfang der Zelle eine farblose Zone, welche sich gegen den Kern hin verbreitert. Bisweilen traf jch auch rothe Blutkörperchen, deren Hämoglobin zerklüftet war, so dass das farblose Stroma mehrere grössere und kleinere grünliche, stark glänzende Kugeln einschloss. Das Endstadium des Entfärbungsprozesses repräsentiren offenbar die zahlreich vorhandenen Blutscheibeu, welche deutliche Kern- und Stromacontouren besitzen, aber vollständig farblos sind. Den Eintritt dieses vollkommenen Schwundes des Hämoglobins hatte ich nicht Gelegenheit zu beobachten. Der Austritt des Farbstoffes vollzieht sich nicht nur an den vollständigen, ovalen oder abgerundeten Zellen, sondern auch an ihren Schnürstücken. Hand in Hand mit der Entfärbung geht das Auftreten glänzender, kugliger Tropfen von intensiver grünlich gelber Farbe, welche vollkommen den erwähnten Kugeln gleichen, die bisweilen im Stroma der rothen Körperchen zu treffen sind, und welche in der umgebenden, durchaus farblos bleibenden Flüssigkeit schwimmen. In Präparaten, welche mit Müller'scher Flüssigkeit gehärtet waren, fand ich sie als durch Eosin stark färbbare, glänzende Kugeln wieder. Es scheint mir keinem $Z_{\text {weifel zu unter- }}$ liegen, dass diese Tropfen den aus den rothen Blutkörperchen ausgetretenen Farbstoff repräsentiren. Eine Verwechselung mit den runden grünen Gebilden, welche durch Zerschnürung der Scheiben entstanden sind, ist nicht möglich; sie sind vor diesen ausgezeichnet durch eine ungleich stärkere Lichtbrechung und 
eine intensivere Färbung und besitzen Kugelform, welche sie nach gelegentlicher Abplattung an benachbarten Körpern beharrlich wieder annehmen, während jene sich als platt und scheibenförmig dadurch erweisen, dass sie die Contouren darunterliegender Körper durchschimmern lassen and nicht selten starre Falten und Einkerbungen zeigen.

Der geschilderte Vorgang der Concentrirung des Hämoglobins innerhalb seines Trägers und des schliesslichen vollständigen Verschwindens aus demselben besitzt eine unverkennbare Aehnlichkeit mit den Erscheinungen, welche sich an den rothen Blutkörperchen der Frösche und Tritonen nach Zusatz von 2 pCt. Borsäure oder gewissen Salzlösungen abspielen: Der Farbstoff zieht sich als geformte Masse nach der Kernstelle hin zurück in Stern- oder Kugelgestalt (Brü cke's Zooid) und kann endlich aus dem farblosen Stroma, wie aus einer weichen, zähflüssigen Masse" entschlüpfen [Hermann $\left.\left.{ }^{1}\right)\right]$.

An Grösse sind die Hämoglobintropfen sehr verschieden; bisweilen erreichen sie ungefähr den doppelten Umfang eines menschlichen rothen Blutkörperchens; indessen überwiegen schon von Anfang an die kleineren Kügelchen und Körner und treten in den folgenden Tagen im Vergleich za jenen noch reichlicher auf. Es scheint danach, dass die grossen Tropfen vor ihrer Umwandlung meist in kleinere zerfallen; einmal konnte ich diesen Vorgang, welcher sich im Innern eines Leukocyten abspielte, unter dem Mikroskop beobachten, derart, dass eine grosse, grünliche Kugel vom Arm einer amöboiden Zelle erfasst und in das Protoplasma des letzteren hereingezogen wurde, dann eine granulirte Oberfläche bekam und schliesslich in eine Menge kleiner Tröpfchen zerstob, welche sich im Protoplasma vertheilten.

Für den ausgetretenen Farbstoff scheint die Pigmentmetamorphose das unvermeidliche Schicksal zu sein, wenigstens fand ich denselben mit zunehmendem Alter der Plättchen sich immer mehr verringern, während die Menge des Pigmentes wuchs, bis er schliesslich ganz verschwand. Nach dem Austritt aus dem Stroma wird ein Theil der Hämoglobintropfen von Leukocyten umschlossen, um in ihnen die Umwandelung zu vollenden; diese

1) Hermann, Handbuch der Physiologie. Bd. IV. 1. Theil. 1880. 
Zellen selbst scheinen durch die Aufnalume in ihren Lebensfunctionen in keiner Weise beeinträchtigt $z u$ werden, ihre amöboiden Bewegungen dauern fort und sie nehmen an allen Veränderungen Theil, welche die äbrigen Wanderzellen durchlaufen, sie werden $z u$ epithelioiden und spindeligen Zelien, die schliesslich einen fixen Standort einnehmen. Indessen ist der Act des Eintrittes in contractile Elemente offenbar nicht nothwendige Vorbedingung für die weitere Metamorphose; denn man trifft in Plättchen jeden Alters zahlreiche freie Tropfen bezw. Pigmentkörner in den Maschen zerstreut, ohne dass es den Anschein hat, als seien sie durch Zerfall ihrer Träger frei geworden. Der Vebergang zur braunen Farbe erfolgt allmählich and nicht an allen Kügelchen gleichzeitig. Vom dritten Tag nach dem Einlegen des Plättchens an treten erst wenige gelbbraune Körnchen auf, welche nach und nach an Menge zumehmen. Sehr bezeichnend dafür, dass in der That die kleinen grünen Kügelchen die Vorstufe des Pigmentes bilden, sind die Fälle, in denen innerhalb e iner frei oder im Protoplasma eines Leukocyten liegenden Gruppe ron solchen einige gelbbraunen Farbenton tragen, andere aber unverändert grünlich erscheinen, oder nur einen leichten Stich in's Braune zcigen. Derartige zugleich hämoglobin- und pigmentführende Zellen erinnern an die Gebilde, welche Lieberk ühn ${ }^{1}$ ) im Tritonenblut beobachtete und als weisse Blutkörperchen beschreibt, die Pigment „in Begleitung von fettartigen Körnchen“ einschliessen.

Nach seiner morphologischen Vollendung liegt das Pigment in Form kleiner Körner von goldgelber Farbe and starkem Glanz an Zellen gebunden oder frei in den Maschen des Plättchens and häufig zugleich innerhalb des dasselbe umgebenden Thrombus. Diese letztere Localisation kann nicht befremden, da das Blut, mit welchem die Plättchen getränkt werden, sich nicht nur in den Maschen desselben festsetzt, sondern auch seine Oberfläche bedeckt; diese äusserlich adhärirenden Massen werden durch die um das Plättchen herum erfolgende Lymphgerinnung fixirt und stellen sich auf Schnittpräparaten theils als ausgedehnte Blutthromben dar, welche zwischen Plättchen und Lymphthrom-

1) Lieberkühn, Ueber die farblosen Blutkörper. Sitzungsber. d. Marburger naturwiss. Gesellsch. 1868. 
bus eingeschaltet sind, oder als heerdförmige Einlagerungen in den letzteren selbst.

Bisher ist als das wesentliche Substrat des Pigmentes das tropfenförmig ausgetretene Hämoglobin hingestellt worden; es fragt sich, ob auch die abgeschnürten, stromahaltigen Stücke der rothen Blutkörperchen zur Pigmentbildung beitragen können. Eine grosse Bedeutung für den Prozess scheinen dieselben nicht zu besitzen, denu ihre Zahl war an allen Objecten gering. Zweifellos kann sich an ihnen, wie an den ganzen Blutkörperchen, das Hämoglobin vom Stroma nachträglich noch trennen und die Umwandlung in der geschilderten Weise durchmachen; wenn ich diesen Vorgang auch nicht direct unter dem Mikroskop sich abspielen sah, so fand ich doch häufig genug an frischen, wie gehärteten Präparaten die verschiedenen Stadien seiner Entwickelung in Form von theilweise oder ganz entfärbten Scheiben. Dass aber ein abgeschnürtes Stück in toto sich zu einem Pigmentkorn bräunen kann;, dafür habe ich in meinen Beobachtungen keine Anhaltspunkte gefundeo. Die Pigmentmetamorphose scheint bei der von mir benutzten Versuchsanordnung kein nothwendiges Ereigniss für alle rothen Blutkörperchen za sein; auch in den spätesten Perioden wurden dieselben noch in den Maschenräumen des Plättchens sowohl, als innerhalb des Thrombus isolirt liegend oder zu Gruppen vereinigt getroffen, in unveränderter Form oder abgerundet, mit tingirbarem Kern und einem Stroma, das in Farbe und Färbbarkeit vollständig gleiches Verhalten zeigte, wie das der frischen, innerhalb der Gefässe gelegenen Blutscheiben; bei anderen rief Eosinbehandlung eine mehr kupferfarbene Nuance hervor, bei noch anderen wurde der strohgelbe Ton durch Eosin nicht verändert. In demselben $\mathrm{Zu}$ stand fanden sich gewöhnlich auch noch mehr oder weniger zahlreiche kreisrunde Schnürstücke vor, so dass mir ihre Fähigkeit ohne vorherige Trennung des Hämoglobins vom Stroma zu Pigment zu werden, zweifelhaft erscheint.

Den Pigmentbildungsvorgang, welchen J. Arnold in der Froschzunge nach der Diapedese beschreibt, dass sich innerhalb der rothen Blutkörperchen, besonders der abgerundeten, braune Körner entwickeln, konnte ich am lebenden Präparat nicht beobachten. Den Endproducten nach lässt sich nicht bestimmen, 
eine wie grosse Rolle er gespielt laben mag, da dieselben, ruude kernhaltige Zellen mit amorphem Pigment, in farblosen Protoplasma von denen nicht zu unterscheiden sein werden, welche aus der Lmwandelung des Hämoglobins in epithelioid gewordenen Wanderzellen resultiren.

Die morphologische und die chemische Ausbildung des körnigen eisenhaltigen Pigmentes gehen getrennte Wege. Die Eisenreaction müht sich lange vergebens, an den gelbbraunen Körnern irgend welche Farbenveränderung hervorzurufen. Das Pigment ist auf dem Wege, das Stadium der positiven Reaction zu erreichen, aber nur ein kleiner Theil dringt in den Zeiträumen, welche ihm meine Versuche boten, bis zu diesem Ziele vor, der grössere ist trotz der morphologischen Vollendung in chemischer Beziehung auf einem früheren Punkte stehen geblieben. Die jüngsten Plättchen, an deren Inhalt wenigstens theilweise, der mikrochemisch nachweisbare Eisengehalt zu Tage trat, hatten 46 Tage im Lymphsacke gelegen. In allen aus früheren Perioden stammenden Objecten-war die Reaction vollständig resultatlos. Ich würde bereit sein, 6-7 Wochen für die zur Erreichung des Zieles erforderliche Minimalzeit zu halten, wenn alle jenseits dieses Termins liegenden Plättchen sich für die Reaction empfänglich erwiesen hätten. Ueberraschender Weise aber blieb dieselbe an vielen von ihnen wieder aus: Es bläute sich in den 56 Tage alten Objecten ein Theil des Pigmentes, welches dem Thrombus angehörte, während ein anderer, der im Plättchen selbst lag, unverändert blieb. Bei den vom 65. Tage stammenden Plättchen eines Frosches enthielt das eine nur ganz wenig reagirende, meist unempfängliche Körner, die anderen zwei nur die letzteren. In den ältesten Plättchen endlich, welche 70 und 100 Tage im Lymphsacke gelegen hatten, ging kein einziges Körnchen des reichlichen Pigmentes den Farbenwechsel ein.

Es giebt also beim Frosch ein körniges Pigment, welches kein mikrochemisch nachweisbares Eisen enthält, obwohl es genetisch and morphologisch vom Hämosiderin nicht unterschieden ist, und fast möchte es scheinen, als ob der Eintritt der Reaction nur von Zufälligkeiten abhinge, und keine Gesetzmässigkeit dabei obwalte. Indessen finde ich in allen meinen Präparaten eine auffallende Uebereinstimmung zwischen dem Auftreten der 
Eisenreaction und der Entwickelung vou Blutgefässen. Nachdem innerhalb der ersten Tage, während welcher das Pigment morphologisch fertig gestellt wird, sich um das Plättchen herum der meist ziemlich dicke Lymphthrombus ausgebildet hat, sind alle in den Maschen und im Thrombus enthaltenen zelligen Elemente jedem lebhafteren Stoffwechsel entrückt. In diesem $\mathrm{Zu}$ stande verharrt das Plättchen Wochen lang, während deren die eingedrungenen Leukocyten sich zu epithelioiden und Riesenzellen umwandeln. Mit der 5. Woche frühestens wachsen von der Umgebung aus Blutgefässe in den Thrombus hinein, welche anfangs nur in den äussersten Schichten liegen und später gegen das Plättchen zu vorrücken.

Es scheint mir, dass das Erwachen der Eisenreaction mit dem neuen Stoffwechsel, welcher durch die Vascularisation im Plättchen auflebt, in Zusammenhang zu bringen ist. Dieses Abhängigkeitsverhältniss blickt aus allen Versuchen hervor: Das sich bläuende Pigment gehört ausschliessltch solchen Plättchen an, deren Thromben reichliche Gefässe enthalten; demgegenüber fällt in allen den Präparaten, welche älteren Datums als jene sind und doch keine Reaction zeigen, auf, dass die Vascularisation entweder vollständig fehlt, oder nur in Form vereinzelter Gefässe die äussersten Thrombusschichten betrifft. In den reichlich von Blut durchströmten Präparaten stellt sich der Farbenwechsel zuerst an dem Theil des Pigmentes ein, welcher dem Thrombus, besonders dessen oberflächlicheren Schichten, angehört; dagegen blieben die in den Plättchenmaschen selbst liegenden Körner in allen meinen Versuchen unempfünglich, entsprechend der Ausbreitung der Gefässentwickelung, welche zuerst und am ausgiebigsten in der äusseren Zone des Thrombus vor sich geht. Dass das sich bläuende Pigment wirklich dasselbe ist, welches Wochen lang ohne Reaction an demselben Flecke gelegen hat, and nicht etwa erst mit den Gefässen eingewandert ist, geht daraus hervor, dass Plättchen, welche leer in den Lymphsack eingeführt wurden, auch nach der Vascularisation frei von Pigment bleiben.

Unter diesen Verhältnissen gewinnt - auf das Froschblut angewendet - die Einwirkung des lebenden Gewebes, welche Neumann als Grundbedingung für die Entwickelung des Hämo- 
siderins aufgestellt hat, eine noch umfassendere Bedeutung, als Neumanu solbst annimmt. Die Lebensfähigkeit des Gewebes, in welchem dio rothen Blutkörperchen ihre Pigmentmetamorphose durchlaufen, giebt nicht allein von vornherein die Directive dafür, ob die körnige eisenhaltige, $d$. h. auf Eisen reagirende, oder die krystallinische eisenfreie Form sich bilden soll. Vielmehr bedarf es der fortdauernden Einwirkung des lebendigen Stoffwechsels, um das so angelegte Pigment auch zu dem chemischen Endziel seiner Metamorphose zu führen, an welchem es sich durch seine mikrochemische Reaction als Hämosiderin offenbart.

Bei den Kaninchenversuchen ging ich von der Absicht aus, in Verwerthung der Resultate Fleiner's ${ }^{1}$ ) zu gleicher Zeit Blut in zwei verschiedene Organe zu schaffen, um es in ihnen der Pigmentmetamorphose auszusetzen. Fleiner hat gezeigt, dass bei den Versuchsthieren ein Theil des Blutes, welches durch Aspiration in die Lungen gelangt, augenblicklich von den Lymphbahnen aufgenommen wird und bis in die Bronchialdrüsen vordringt, während der andere Theil im Lungengewebe liegen bleibt. So glaubte ich durch den einen Act künstlicher Aspiration ein Depot rother Blutkörperchen in beiden Organen anlegen und verfolgen zu können, ob die Umwandelung in gleicher Weise und in der gleichen Zeit vor sich gehe. Indessen batte ich nicht immer denselben Erfolg wie Fleiner. Derselbe führte die Aspiration herbei, indem er die Halsgefässe und die Trachea gleichzeitig durchtrennte, oder indem er grössere Quantitüten Blutes auf einmal in die Trachea eingoss. In jedem Falle war die Folge eine tiefe, ausgiebige Athmung, welche offenbar auf dem Weitertransport in den Lymphwegen beschleunigend einwirkte. Da meine Versuchsthiere nach Beendigung der Aspiration noch längere Zeit am Leben bleiben sollten, musste ich die Menge des eingeführten Blutes beschränken und den Act der Einflössung selbst möglichst in die Länge ziehen. Ich spritzte nach Anlegung einer kleinen Schnittwunde durch die Weichtheile vor der Trachea in die letztere mittelst der Pravaz'schen Spritze frisches defibrinirtes Hammelblut ein und zwar in Portionen von

1) W. Fleiner, Ueber die Resorption corpusculärer Elemente durch Lungen und Pleuren. Dieses Archiv Bd.112. 1888. 
$1 \mathrm{ccm}$; die Gesammtmenge betrug $8 \mathrm{~cm}$ und wurde in einem Zeitraum von ca. 2 Stunden verabreicht. So änderten die Thiere kaum ihre Athmung in Folge der Einspritzung, sondem respirirten ruhig und flach. Daraus glaube ich es erklären zu können, dass die Untersuchung der Bronchialdrüsen auch der nach Fleiner am meisten zur Aufnahme disponirten, auf rothe Blutkörperchen bezw. seine Umwandelungsproducte in den meisten Fällen negativ ausfiel und ich allein auf das in den Lungen selbst liegen Gebliebene angewiesen war. Das Letztere trat ausnahmslos in grosser Menge auf, so dass ein genaues Studium der verschiedenen Stufen der Metamorphose möglich war.

Einer mit der meinigen übereinstimmenden Versuchsanordnung hat sich Sommerbrodt ${ }^{1}$ ) bedient, um die Bedeutung des in die Luftwege ergossenen Blutes für die Entstehung der Lungenschwindsucht kennen zu lernen; er sammelte bei dieser Gelegenheit Erfahrungen über die Veränderungen der farbigen Blutkörperchen.

Aus der Reihe der 46 Kaninchen, an welchen ich experimentirte, habe ich für die Mittheilung der Versuchsprotocolle solche Fälle ausgesucht, welche sich durch Vergleichung mit gleichaltrigen als typische Repräsentanten der einzelnen Stadien erwiesen. Nur in den spätesten Perioden habe ich die Veränderungen an je einem Falle untersucht; die Sicherheit dafür, dass keine Zufälligkeiten in's Spiel kamen, lag darin, dass jeder derselben eine Steigerung des Prozesses gegenüber dem zeitlich vorhergehenden aufwies, also sowohl durch seinen Vorgänger, als seinen Nachfolger controlirt wurde.

\section{8 stündiger Versuch.}

Kanincben 2, Härtung in Müller"seher Flüssigkeit. Rechter Unterlappen.

In der Ungebung des Hilus ist das Gewebe mit reichlichen rothen Blutkörperchen erfüllt, nach dem vorderen Theil der Lunge zu nimmt die Menge derselben ab. An eituzelnen Stellen ist ibre Anhäufung über einen grösseren Bezirk so gleichmässig, dass die Alveolarsepten nur noch durch Reihen gefärbter Kerne, welche durch den Blutheerd ziehen, angedeutet sind; es scheint also, als ob hier die Wandungen wie die Lumina die Blutkörperchen aufgenommen hätten. Wo die Ansammlung weniger dicht und die Structur

1) Sommerbrodt, Hat das in die Luftwege ergossene Blut ätiologische Bedeutung für die Lungenschwindsucht? Dieses Arcbir Bd. 55. 1872. 
weniger verwischt ist, sieht man die Blutkörperchen in mehr oder weniger reicher Menge die Lumina erfüllen, während in der Regel die Septen frei sind; eine Entscheidung über den letzteren Punkt erschwert die pralle Füllung der Lungencapillaren. Neben den rothen Blutkörperchen treten in vielen Alveolen in wechselnder Zahl Zellen auf, zum Theil kleine lymphatische Elemente, in der Mehrzabl grosse mit bläschenförnigem Kern und breitem Protoplasmasaum. An vielen Stellen sind die interalveolären Septen verbreitert, sehr zellreich. An den weniger dichtstehenden Heerden lassen sich die Formen der rothen Blutkörperchen studiren. Die grosse Mebrzahl scheint unverändert an Grösse, wie Gestalt; bisweilen ist sogar die Scheibenform mit dem centralen Nabel noeh sichtbar. Ihre Farbe ist nach Eosinbehandlung der der circulirenden Blutkörperchen gleich, ein mässig glänzendes, gelbliches Roth. Ein anderer, wenn auch relativ kleiner Theil aber ist von diesen merklich verschieden; die auffallendste Differenz liegt in dem Umfange: Manche überschreiten die Grösse eines rothen Blutkörperchens und reichen bis zum Doppelten derselben heran; indessen sind diese selten, und die kleinere Form präralirt, deren Extrem durch Körner repräsentirt wird, welche ungefähr den vierten Raumtheil eines rothen Blutkörperchens einnebmen. Oft ist der Unfang das Einzige, was diese Gebilde vor den gewöhnlichen Blutscheiben auszeicbnet; jedoch kommt bisweilen noch ein Unterschied im Effect der Eosinfärbung hinzu, derart, dass an jenen blutkörperähnlichen Gebilden weniger der gelblichrothe Ton, als ein dunkleres Rosa hervorgerufen wird; bei einigen bildet ein weiteres Merkmal die stärkere Lichtbrechung. Die rothen Blutkörperchen und die ihnen ähnlichen Gebilde liegen in der Hauptsache frei in den Alveolen; nur ein kleiner Theil findet sich in dem Protoplasma jener epithelioiden und kleinen runden Zellen, meist nur zu wenigen in jeder derselben, seltener sie reichlich erfüllend; im etzter en Falle treten innerbalb einer und derselben Zelle oft die verschiedensten Grössenformen auf.

\section{3 tägiger Versuch.}

Kaninchen 20. Müller'sche Flüssigkeit. Linker Oberlappen.

In der Nähe des Hilus sind die Alveolarwände mit ihren strotzend gefüllten Capillaren viefach einander genähert und die Lumina dadurch spaltförmig verengt, oder vollständig verschwunden. In den peripherischen Schichten, nahe der Pleura tritt nicht selten stärkerer Zellreichthum und damit Verbreiterung der Septen auf. Die mehr oder weniger verengten Alveolen des an den Hilus grenzenden Lungenbezirkes, spärlicher der übrigen Abschnitte, enthalten rothe Blutkörperchen. Zum Theil weichen dieselben in nichts von dem normalen Aussehen ab; neben ihnen aber trift man noch zablreicher, als im vorigen Versuche, die dort beschriebenen grösseren und kleineren kugligen Gebilde mit stärkerem Glanz und, nach Eosinbehandlung, dunkler Rosafarbe. Manche Kugeln der verschiedenen Grössenformen werden durch Eosin nicht beeinflusst, sondern behalten den strohgelben Ton bei, welchen sie in den mit Kernfärbemitteln, ఇ. B. Alauncarmin, ting': ten 
Schnitten zeigen. Diese Blutkörperchen und blutkörperchenähnlichen Gebilde liegen zum grossen Theil frei im Alveolarlumen, zum anderen eingeschlossen in die grossen runden, epithelioiden Zellen oder kleine Lenkocyten, bisweilen nur vereinzelt, meist in reichlicher Zahl dieselben erfüllend, stets so, dass der Kern frei bleibt. Im Lungengewebe selbst, auch in den Lymphknötchen, finden sich keine rothen Blutkörperchen.

Kaninchen 39. Alkobol. Rechter Oberlappen.

Auf dem Horizontalschnitt ist die dem Hilus benachbarte Hälfte des Lungengewebes fast voliständig atelectatisch, die nach dem Vorderrand $z u$ liegende lufthaltig, durch ziemlich scharfe Grenze gegen die erstere abgesetzt. Innerhalb des atelectatischen Abschnittes finden sich nur wenige Inseln mit offenen Alveolen; in ihnen sind nicht selten die interalveolären Septen durch zellige Infiltration verbreitert. Das luftleere Gewebe ist sehr reich an Zellen, unter welchen die mit kleinen runcien oder grossen bläschenförmigen Kernen vorherrschen. Eine Andeutung von Architectur ist bisweilen vorbanden derart, dass die grösseren Zellen Nester von ungefähr dem Umfang der Alveolarlumina bilden, zwischen denen Züge mit kleinen zelligen Elementen verlaufen. Hanptsächlich in den offenen Alveolargruppen der atelectatischen Partien, spärlicher den vorderen Abschnitten, findet sich das aspirirte Blut wieder. Manche Lumina sind vollkommen damit ausgefüllt, andere enthalten nur geringe Mengen. Die Alveolarepithelien, welche vielfach fehlen, sind dort, wo sie der Wand noch aufsitzen, oft gegen das lumen hin stark prominent. Ueber die rothen Blutkörperchen ist, der Alkoholhärtung wegen, wenig auszusagen; meist erscheinen sie als farblose, nicht tingirbare, ziemlich gleichmässig grosse Scheiben. Sie liegen frei im Lumen; im Protoplasma der grossen epithelioiden Zellen und kleinen runden Zellen, welche in wechselnder Zahl neben ihnen in den Alveolen auftreten, fand ich solche Stromata nur ganz vereinzelt. $A b$ und zu triftt man Gebilde von gleichem oder kieinerem Umfang dazwischen mit hellgelber Farbe und lebhaftem Glanz, die den Eindruck von Pigmentkörnern machen. Die Eisenreaction lässt dieselben unveräudert. In Lumen mancher Bronchien, auch solcher von grösserem Kaliber, liegen ruthe Blutkörperchen. Die Lymphknötchen sind frei ron Einlagerungen; auch die grossen Lymphgefässe neben der Pulmonalarterie enthalten keine rothen Blutkörpercben.

$$
4 \text { tägiger Versuch. }
$$

Kaninchen 33. Müller'sche Flüssigkeit. Rechter Unterlappen.

Den Stammbroncbus und seine Hauptzweige begleitet eine Zone, in welcher der alveoläre Bau grösstentheils verschwunden ist, welche vielmehr ein gleichmässig sehr zellreiches Gewebe darstellt, unter dessen zelligen Elementen die leukocytären und die epitbelioiden im Vordergrund steben, Wo noch die alveoläre Structur sich findet, liegen in vielen der Lumina Zellen derselben Formen, bald isolirt, bald so dicht, dass sie die Hohlräume vollkommen ausfüllende Pfröpfe bilden. In allen Theilen des Schnittes trifft man das eingefübrte Blat an: Es erfült die Alveolen in wechseluder Reich- 
lichkeit; bisweilen finden sich Blutheerde von grösserer Ausdebnung und unregelmässiger Gestalt, innerhalb deren jede Andeutung ron Scheidewänden vermisst wird. Die reichliche Füllung der Blutgefässe verbietet ein sicheres Urtheil darüber, ob auch in das Gewebe ein Tbeil des aspirirten Blutes eingedrungen ist. Die grösseren Bindegewebsanhäufungen um die Alveolargänge und die Lympbläötchen sind frei von Einlagerungen. Die rothen Blutbörperchen zeigen dieselben Differenzen in Grösse, Färbbarkeit und Lichtbrechungsvermögen, wie im vorigen Falle. Der grösste Theil von ibnen liegt frei im Lumen, ein anderer im Protoplasma epithelioider Zellen, bald vereinzelt, bald zu vielen in jeder derselben. In einzelnen Alveolen liegt fertiges Pigment, bäufiger im Innern von Zellen, als neben diesen; es tritt ausschliesslich in Form von meisi runden Körnchen auf, deren Grösse in denselben Grenzen schwankt, wie die der beschriebenen "Blutkörperchen". Itre Farbe ist ein helles Gelb, das von Eosin nicht beeinflusst wird, ihr Glanz ein sehr intensiver.

Kaninchen 46. Alkohol. Rechter Unterlappen

Die Veränderungen des Lungengewebes in der Ungebung des Hauptbronchus und der grossen Gefässe gleichen im Allgemeinen denen bei Kaninchen 33. Die Alveolarlumina entbalten zablreiche rothe Blutsörperchen, grosse epithelioide und kleine lymphatische Zellen; zwischen diesen findet sich vielfach geronnenes Exsudat. Viele der epithelioiden Elemente sind sehr gross, gequollen, ihr Kern oft nur schwer färbbar, oder ganz feblend. Im Protoplasma eines grossen Theiles der Zellen liegen Gebilde von runder oder eckiger Form, blassgelber Farbe und starkem Glanz eingeschlossen, die an Umfang relativ selten einem rothen Blutkörperchen gleichkommen, hänfiger kleiner sind und mehr oder weniger feine Körner darstellen. Dieselben füllen ihre Träger bald in reichlicher Zahl, bald treten sie nur vereinzelt auf, den ausgesprochenen Charakter der rothen Blutkörperchen zeigen diese gelben Pjgmentkugeln niemals. $O b$ ausserhalb der Zellen noch Pigment vorbanden ist, lässt sich schwer entscheiden, da der Contrast zwischen der ihm eigenen hellgelben Farbe und der der leicht tingirten Exsudatmassen undeutlich ist. Die grossen Lymphgefässe, welche neben der Hauptarterie verlaufen, enthalten geronnene Lymphe und Leukocyten, aber keine rothen Blutkörperchen oder Pigmentkörner. Frei von jeder Einlagerung sind die interalveolären Septa und die pulmonalen Lymphknötchen.

Nach Einwirkung des Ferrocyankali-Salzsäuregemisches findet sich ausgedehnte Blaufärbung. An Stelle der gelben Pigmentkörner liegen Kugeln von tiefer, gesättigt blauer Farbe; indessen hat sich dieser Wechsel nicht an allem vorbandenen Pigment vollzogen, viele der Körner haben ibr ursprüngliches Aussehen nuverändert beibehalten und liegen nicht selten mit reagirenden in derselben Zelle eingeschlossen. Bisweilen tritt diffuse Bläunng zu Tage, an deren Stelle auch bei der Controlreaction mit Schwefelammonium grauschwarze Färbung sich findet; sie erstreckt sich selten über eine ganze Zelle, meist nimmt sie nur einen Theil derselben, mit Vorliebe eine halbmondförmige Randzone, ein. Am bäufigsten betrifft sie solche 
Zellen, welche sehr gross und gequollen sind und keinen oder nur einen schwach färbbaren Kern besitzen, kurz, welche allem Anschein nach im Untergange begriffen sind. Freiliegende blaue Körner fördert die Reaction nicht zu Tage; die rothen Blutkörperchen bleiben durchweg unverändert.

\section{7 tagiger Versuch.}

Kaninchen 45. Alkohol. Rechter Oberlappen.

In der Nähe des Hilus ist das Gewebe luftarm, sehr zellreich, aus runden und länglichen Zellen zusammengesetzt, in welche Nester grösserel epithelioider eingesprengt. sind; diese Nester entsprechen allem Anschein nach dem Lumen früherer Alveolen. Je entfernter vom Hilus, desto mehr nimmt der Luftgehalt $z u$; zunächst wird der alveoläre Bau wieder deutlich, nur sind die interalveolären Scheidewände sebr breit und von vielen Zellen durchsetzt; viele Alveolen enthalten noch Pfröpfe grosser Zellen. Die subpleuralen Gewebszonen erscheinen durchaus unverändert. Ueber den ganzen Schnitt vertheilt findet sich viel Pigment, am reichlichsten in den atelectatischen Hiluspartien. Es liegt hier in den erwähnten Nestern, zum grössten Theil in das Protoplasma der Zellen eingeschlossen, zum kleineren neben diesen. In geringer Zahl trifft man in den Alveolen noch rothe Blutkörperchen, gewöhnlich - in Folge der Alkoholhärtung - als farblose Stromata. Die sehr zahlreichen Lymphknötchen sind vollständig frei von Einlagerungen. Die Form der Pigmentkörner ist rund oder etwas eckig, ihr Unfang sehr wechselnd: Die grössten erreichen oder übertreffen sogar den eines rothen Blutkörperchens, jedoch sind sie nicht häufig, und die kleineren Sorten, bis zu staubartigen Gebilden herab, überwiegen. Die einzelnen Zellen enthalten selten spärliche Rörner, meist sehr reichliche, und jede vereinigt in der Regel die verschiedensten Grössenformen in ibrem Protoplasma. Die Farbe des Pigmentes ist ein blasses Gelb, bisweilen zum Goldgelb neigend; allen Körnern ist ein intensiver Glanz eigen.

Die Eisenreaction wird sehr verschieden beantwortet. Ein Theil des Pigmentes behält seine ursprängliche Farbe unverändert bei; an dem grösseren Theil indessen vollzieht sich ein Farbenwechsel, freilich in selir ungleicher Intensität; viele Körner nehmen ein reines, tiefes Blau an, andere werden mehr bellblangrün, noch andere bekommen nur einen Anflug von Grün, ohne dass dadurch der gelbe Grundton vollkommen verdeckt wird. Diese Differenzen sind unabhängig von dem Umfange der Körner, bald zeigen die grössten die ausgiebigste Reaction und die kleinen bleiben unverändert, bald ist das Verhältniss das umgekehrte. Auch ihre Lagerung hat keinen Einfluss darauf, oft treten sogar am Inhalt einer und derselben Zelle die verschiedensten Grade der Reaction auf. Einzelne der epithelioiden Zellen nehmen diffuse Färbung an, auch bei der Controlreaction mit Scbwefelammonium.

$$
11 \text { tägiger Versucb. }
$$

Kaninchen 11. Müller'sche Flüssigkeit. Rechter Oberlappen. In der Näbe des Hilus ist das Gewebe in grosser Ausdehnung atelecta- 
tisch, von gleicher Beschaffenheit, wie bei Kaninchen 45 , mit. nur wenigen offenen Alveolen; nach der Peripherie zu wehrt sich die Zahl der letzteren. Jeder Schnitt weist viel $\mathbf{P}$ igment auf, in den luftleeren und lufthaltigen Partien in gleicher Menge, welches fast durchweg im Innern von Zellen liegt. Es tritt in Gestait von Körnem auf, deren Umfang zwischen den früher beschriebenen Grenzen variirt und die runde oder eckige Gestalt besitzen. Ihre Farbe ist etwas dunkler, als in den früheren Fällen, wehr goldgelb, ihr Glanz sehr intensiv. Die am reichlichsten vertretene Sorte der pigmentführendeu Zellen ist epithelioider Natur, mit einem Kern und reichlichem Protoplasma; daneben kommen Formen vor, wo ein ebenso grosses oder umfangreicheres Protoplasma 2 oder 3 Kerne umschliesst und endlich, an Zahl gegenüber diesen sehr zurücktretend, Riesenzellen, grosse vielgestaltige Protoplasmahaufen mit zahlreichen, bald central, bald peripherisch gelegenen Kernen. Die beschriebenen Zellen enthalten bisweilen nur ein Pigmentkorn, in der Regel mebrere, die deutlich von einander getrennt im Protoplasma sich vertheilen, oder eine Polgegend einnehmen; es kommt vor, dass eine Zelle so dicht erfült ist, dass vom Protoplasma nichts mehr zu sehen ist, und die einzelnen Körner weniger durch ihre Contouren, als thre stark glänzenden Kuppen von einander zu scheiden sind; in solchen Fällen kann selbst der Anschein von diffus gefärbten granulirten Zellen erweckt werden. Bisweilen trifft dieses Aussehen nur eine Hälfte des Protoplasmas, in der anderen löst sich die glänzende granulirte Pigunentmasse in einzelne weniger dicht stehende Körner auf. In den lufthaltigen Bezirken sind die Pigmentzellen meist in den Alveolen localisirt, wo sie isolirt, oder zu mehreren beisammen liegen. Viel seltener sind sie in das Gewebe selbst eingedrungen und in den Alveolarsepten und deren Knotenpunkten abgelagert; vollständig frei daron sind die lymphatischen Knötchen. $0 b$ in den luftleeren Partien die Pigmentansammlungen ebenfalls dem ebemaligen Lumen von Alveolen entsprechen, ist schwer zu entscheiden; sie erscheinen hier in isolirten oder gruppirten Zellen in das gleichmässig zellreiche Gewebe eingefügt. Eosingefärbte rothe Blutkörperchen liegen ganz vereinzelt in den Alveolen.

\section{4tägiger. Versuch.}

Kaninchen 40. Alkohol. Rechter Oberlappen.

Die luftleeren Partien längs des Stammbronchus und der Hauptgefässe haben das Ansehen eines zellreichen, stark vascularisirten, gleichmässigen Bindegewebes, welches noch einzelne offene Alveolen und Gruppen von solchen einschliesst. In diesen, wie in denen der peripherischen luftreichen Bezirke liegen voluminöse Zellen epithelioiden Charakters, bald zu mehreren das ganze Lumen erfüllend, bald isolirt, welche fast ausnahmslos Pigment einschliessen. Mitten im atelectatischen Gewebe trifft man hier und da ebensolche Zellen einzeln oder in Gruppen, ferner kommen sie auch in den Alveolarsepten und in einzelnen Lymphknötchen vor. Das freie Pigment tritt an Menge bedeutend binter dem eingeschlossenen zurück. Die Grösse der Körner unterliegt denselben Schwankungen, wie in den früheren 
Fällen; der kleine Typus berrscht vor; die Farbe ist ein helles Gelb oder Goldgelb.

Die Eisenreaction wirkt auf fast das ganze Pigment ein, nur ein ganz geringer Theil widersteht ibr. Unter den durch sie hervorgerufenen Farben prävalirt das reine, gesättigte Blau; den Nuancen, welche sich bei Kaninchen 45 reichlich fanden, unterliegen nur wenige Körner.

\section{2 tägiger Versuch,}

Kaninchen 4. Mn̈ller'sche Flüssigkeit. Rechter Unterlappen.

Den Hauptbronchus ungiebt eine schmale atelectatische Zone, welche ganz frei von Pigment ist. Sehr viel solches aber liegt im übrigen Gewebe vertbeilt. Es tritt auf in Form ziemlich scharf begrenzter Heerde, innerbalb deren es nicht sebr dicht liegt, so dass der Charakter des Gewebes, welches dieselben beherbergt, leicht zu erkennen ist. Es handelt sich ohne Ausnahme um Gruppen von gefüllten Alveolen; sie werden durch die fast überall pigmentfreien Bindegewebssepten in einzelne gefärbte Felder zerlegt. Diese Alveolarpfröpfe setzen sich in der Hauptsacbe aus Zellen verschiedener Grösse mit deutlichem Kern zusammen, welche die Körner einscbliessen, während nur eine geringe Menge der letzteren frei zwiscben ihnen zerstreut liegt. Die Farbe des ausschliesslich körnigen Pigmentes ist ein reines, glänzendes Goldgelb. Die Grösse variirt, wie in den früheren Fällen, ohne Prävalenz einer Sorte; die Form ist rund oder unregelmässig eckig. In den Alveolarsepten, welche an die Pigmentnester anschliessen, liegen nur spärliche Körner, wie es scheint, ansserhalb von Zellen. Frei davon sind die Lymphknötchen und Bindegewebsanhäufungen um die Alveolargänge. Von rothen Blutkörperchen oder solchen noch in der Trmwandlung begriffenen ist Dirgends Etwas zu sehen.

Kaninchen 43. Alkobol. Rechter Unterlappen.

In der Nähe des Hilus sind die Alveolen durch bindegewebige Verbreiterung der Septen weiter auseinandergerückt; ausgedehnte atelectatische Bezirke fehlen. Die Hiluspartien enthalten viel Pigment, welches meist in streifenförmigen, den interalveolären Leisten entsprechenden Zügen angeord* net ist, am reichlichsten in der Urogebung der grossen Gefäss- und Bronchialstämme. Seltener findet es sich in Form rundlicher Heerde; wo solche getroffen werden, grenzen sie an einen Alveolargang oder ein Gefäss an und sind meist von einer Biadegewebszone umgeben, so dass es den Anschein hat, als seien sie in Bindegewebsknötchen eingefügt; die lymphatisehen Heerde sind frei davon. Deutliche pigmenthaltige Alveolarpfröpfe finden sich nirgends, nur vereinzelte Pigmentzellen kommen hier und da in den Hohlräumen vor. In Form, Grösse, Farbe und Glanz gleichen die Körner denen des vorigen Versucbes. Der grösste Theil von ihnen liegt in meist kleinen Zellen eingeschlossen.

Die Eisenreaction ist sehr ergiebig: Sämmtliche Körner gehen den Farbenwechsel ein, und zwar in vollster Intensität; überall tritt ein tiefes, gesättigtes Blau w Tage; die Uebergangsnuancen fehlen. 
7 wöchentlicher Versuch.

Kaninchen 22. Alkohol. Rechter Unterlappen.

Die Atelectase ist gering, auf die näcbste Ungebung der grossen Gefässe und Bronchien beschränkt. Das Pigment liegt theils in grosseren Heerden, welche drei verschiedenen Gewebsarten anzugehören scheiuen. Ein Theil entspricht zweifellos den pulwonalen und subpleuralen Lymphknötchen, wie aus dem den Pigmentbaufen umgebenden Saur lymphatischen Gewebes hervorgeht; indessen sind noch viele derselben vollständig frei von Einlagerungen. Andere gehören den periinfundibulären Bindegewebsanbäufungen an und der Rest repräsentirt ausgefüllte Alveolen. Bisweilen ist es übrigens nicht möglich, die Localisation des Pigmentnestes zu bestimmen, wenn die Körner sehr dicht stehen und weder $z$ wischen ihnen, noch in der Peripherie das Grundgewebe sichtbar ist. Fast alles Pigment ist an Zellen gebunden, die innerhalb der Lymphknötchen die gewöhnlichen lymphoiden Zellen an Grösse bedeutend übertreffen. In Bindegewebe scheinen die fixen Zellen an der Pigmentirung theilzunehmen. Gegenüber diesen grösseren Heerden sind die isolirten Pigmentzellen und die verstreut liegenden Körnchen in der Minderzahl; sie gehören weist den interalveolären Septen an, welche sich an jene anschliessen. Die Farbe ist goldgelb oder gelbbraun, stellenweise tritt eine leichte Beimischung von Schwarz hinza, welche den Körnern ein trübes, unreines Ausseben verleiht. Diffuse Färbung der Zellen und des Gewebes fehlt.

Das gesammte Pigment giebt präcise und intensive Eisenreaction. Im linken Unterlappen, wo die Anordnung des Pigmentes der im rechten gleicht, ist die Neigung der Körner zu dem schwärzlichen Ton noch viel verbreiteter und prägnanter; bei manchen resultirt eine der Sepia ähnliche Farbe, bei anderen kommt sie der durch die Schwefelammoniumreaction erzeugten nabe. Auch diese dunkle Modification reagirt durebweg auf Eisen.

\section{9 wöchentlicher Versucb.}

Kaninchen 19. Alkohol. Rechter Oberlappen.

Die Atelectase ist ausgedehnter als im vorigen Falle und betrifft hauptsächlich die Umgebung der grössten Bronchial- und Gefässstämme; nach der Plenra zu finden sich nur noch einzelne kleinere Heerde; das Gewebe dieser Stellen besteht aus kleinen unregelmässig gestalteten Zellen ohne gesetzmässige Anordnung mit spärlicher Intercellularsubstanz. Die Pigmentheerde gehören meist diesen luftleeren Partien an und den verbreiterten interalveolären Leisten; dadurch, dass sie deren Verlaufe folgen, erscheinen sie verzweigt, oft netzförmig. Die pulmonalen und subpleuralen Lymphknötchen sind leer. Die pigmenthaltigen Zellen des atelectatischen Gewebes sind meist grösser, als die benachbarten Elemente; neben ihnen kommen ziemlich viel freie Körner vor. Die grösseren Schollen, welche den Umfang eines rothen Blutkörperchens erreichen oder überschreiten, sind nicht mehr so reichlich im Vergleich zu den kleinen Körnern, als fiüher; unter diesen letzteren finden sich jetzt auch in grösserer Zahl, als bisher, sehr feine, fast staubfömige 
Gebilde. In der Farbe der Körner ist eine grössere Mannichfaltigkeit aufge* treten: Der bisber gelbbraune Ton findet sich zwar noch reichlich vertreten, aber in verschieden dunklen Nuancen; und bei eben so vielen Körnern ist eine, rothe Beimiscbung hinzugekommen, welche ihnen ein kupferähnliches Aussehen verleiht. Allen ist dabei ein lebhafter, reiner Glanz eigen, der schmutzige, schwäraliche Ton, wie er bei Kaninchen 22 bisweilen auftrat, findet sich nirgends.

Die Eisenreaction führt an sämmtlichen Körnern den Farbenwechsel herbei, keines bleibt unverändert; fast überall kommt das reine Blau zum Vorschein, nur hier und da ein dunkles Grün.

\section{1 wöhentlicher Versuch.}

Kaninchen 21. Alkobol. Rechter Oberlappen.

Die atelectatischen Partien, welche am Hilus beginnen, beschränlen sich nicht nur auf die Umgebung der grossen Bronchien und Gefässe, sondern reichen bisweilen bis zur Pleura der seitlicheu Lungenfläche. Sie bestehen aus einem gleichmässigen, kleinzelligen Bindegewebe. Den Uebergang zum unveränderten Gewebe vermitielt eine Zone, in welcher die Alveolarsepten sebr zellreich und verbreitert, deshalb die Lumina spärlicher, weiter anseinander gerückt sind. Ueber den ganzen Schnitt verbreitet findet sich seb" reichliches börniges Pigment in den atelectatischen Bezirken in geringerel Menge, als in den lufthaltigen, und hier mit Vorliebe dicht unter oder nahe der Pleura. Meist ist es zu umfangreichen, dichterfüllten Gruppen vereinigt, deren einige mit Sicherheit anf ausgefülite Alveolarlumina zu beziehen sind und sich auf dem Durchschnit aus 10-12 Feldern zusammensetzen. Einzelne kleinere Nester gehören den breiten Bindegewebsleisten zwischen den Hohlräumen an; isolirte Körner oder Häufehen von solchen treten nur in der Nachbarschaft der grösseren Heerde auf. Die Anordnung des Pjgmentes, seine Beziehungen zu den Zellen, die Grösse und Farbe der Körner stimmt volkommen mit dem in vorigen Falle Mitgetheilten überein.

Der Erfolg der Eisenreaction ist ein äusserst mannichfaltiger: Ein nicht geringer Theil der Kö'ner wird gar nicht alterirt, bebält seine ursprüngliche Farbe vollständig unverändert bei, und zwar gilt dies von den grössten ebensowohl als von den kleinsten. Andere bekommen einen bisweilen äusserst discreten grünlichen Anfing, welcher schliesslich durch alle Uebergangsstufen in der Intensität der Färbung das Maximum erreicht in den gesättigt tiefblauen Kugeln; die letzteren, wie überhaupt alle höheren Grade der Reaction sind ziemlich sparsam vertreten. Die Differenz in der Intensität bezicht sich einmal auf die Bestandtheile des einzelnen Pigmentheerdes; bisweilen geht das Centrum desselben den Farbenwechsel stärker ein, als die peripherische Zone; andererseits tritt die Verschiedenheit hervor, wenn man die Heerde auf den Durchschnittsgrad ibrer Reaction mit einander vergleicht; in manchen fehlt fast jedes Zeichen der Bläung, nur die geringste Stufe kommt zum Vorschein, in anderen bleibt kein Korn unverändert. 
16 wöcbentlicher Versuch.

Kalinchen 23. Alkohol. Rechter Oberlappen.

Die ziemlich ausgedehnten luftleeren Partien am Hilus sind arm an Pigment, sebr reichliches aber enthält das übrige Gewebe. Die weisten der grossen Heerde liegen subpleural und gehöien grösstentheils den Lymphknötchen an; von den mehr central gelegenen werden ebenfalls einige von einem Ring lymphatischen Gewebes ungeben, andere sind Alveslarpfröpfe, für manche ist eine Entscheidung hierüber nicht möglich. Oft setzen sich von diesen Nestern aus strablige Ausläufer längs der interalveolären Bindegewebsleisten fort. Kleine Häufchen und isolirte Körner trifft man auch fern von ihnen; besonders in die Knotenpunkte der Septen eingesprengt. Der grössere Theil der Körner wird von Zellen eingeschlossen, der kleinere liegt frei. Nicht selten sind maulbeerförmige Klümpchen, an welchen sich weder ein Kern, noch ein umbüllender Protoplasmasaum erkennen lässt. In der Farbe des Pigmentes herrscht der rothbraune Ton gegenüber dem goldgelben und gelbhraunen vor; die Grössenverhältuisse sind ungefähr die gleichen, wie in dem letzten Versuch.

Nach der Eisenreaction zeigen, mit schwacher Vergrösserung betrachtet, manche der Heerde nur einen schwachen blauen Schimmer, andere entbehren einer auffallenden Farbenveränderung. Bei stärkerer Vergrösserung lässt sich an den einzelnen Körnern nur ein äusserst geringer Grad der Verfärbung erkennen, ein leichter Stich in's Grüue, und nur ibre Häufung vermag den Eindruck eines deutlichen Wechsels zu erwecken; spärlich sind die Elemente vertreten, welche einzeln gesehen einen ausgeprägten blauen Ton besitzen, nur vereinzelt die gesättigt blauen. Ein grosser Theil des Pigmentes, welchem die verschiedensten Korngrössen angehören, hat sein unverändertes gelb- oder rothbraunes Aussehen beibebalten. Eine räumliche Sonderung der reagirenden und reactionslosen Körner besteht in Allgemeinen nicht, nur einzelne Heerde sind, wie erwähnt, von der Einwirkung fast rollständig verschont geblieben, in der Regel mischen sich die gebläuten mit den unveränderten Elementen in den Gruppen, oft sogar innerbalb derselben Zelle. Die verstreut liegenden Körner verweigern häufiger die Reaction, als dass sie den Farbenwechsel eingehen.

\section{0wöchentlicher Versuch.}

Kaninchen 28. Alkohol. Rechter Unterlappen.

Ueber die ganze Schnittfäche vertheilt finden sich zahlreiche Pigmentbeerde von rundlicher Form, bei deren Bildung die Lymphknötehen, das periinfundibuläre Bindegewebe und Alveolargruppen concurriren; ausserdem enthalten-einzelne interalveoläre Septen kleine Nester. Der grössere Theil des Pigmentes ist in Zellen eingeschlossen; manche derselben erscbeinen wie bestäubt mit sehr feinen braunen Körnchen; der goldgelbe und gelbbraune Farbenton ist voliständig geschwunden und hat einem kupferähnlichen Rothbraun Platz gemacht, welches ab und zu eine schwärzliche Beimischung zeigt, Die kleinen Körner überwiegen bedeutend die grossen. 


\section{2}

Bei der Eisenreaction nehmen die meisten Heerde im Ganzen eine blaue Färbung an; die starke Vergrösserung löst dieselben auf in tiefblaue Körner, solche vou hellerer oder dunklerer grüner Farbe und endlich solche, welche keine Veränderung erlitten haben. Manche Pigmentgruppen indessen widersteben der Reaction fast vollständig, derart, dass nur ein kleiner Theil ibrer Elemente einen schwachen Anflug erhält.

Im rechten Oberlappen, welcber bezüglich der Anordnung und äusseren Erscheinung des Pigmentes dieselben Verhältnisse zeigt, ist der Erfolg der Eisenreaction ein anderer: Kein Heerd nimmt mehr eine deutlich blaue Färbung an, in jedem sind es nur einzelne Körner, welche einen Farbenwechsel zeigen, und in der Regel besteht dieser nur in einem äusserst discreten grünlichen Anflug, selten in ausgesprochener Bläuung.

25 wöchentlicher Versuch.

Kaninchen 26. Alkohol. Rechter Oberlappen.

Das Pigment ist reichlich, in der Localisation der grossen Nester herrscht dieselbe Mannichialtigkeit, wie bei den letzten Versuchen. In Form, Grösse und Farbe ist kein Unterschied gegen früber zu bemerken.

Die Eisenreaction ist wenig ausgiebig: Wohl nehmen die meisten der Pigmentheerde für das blosse Auge einen schwach bläulichen Schimmer an, doch zeigt das Mikroskop, dass derselbe nur der Effect einer leichten Verfärbung zahlreicher Körner, dass die Veränderung jedes einzelnen derselben äusserst unbedeutend ist. Ein grosser Theil von ihnen bleibt vollkommen unbeeinflusst von der Reaction. Rein blaue Körner kommen selten zum Vorschein.

28 wöchentlicher Versuch.

Kaninchen 24. Alkohol. Rechter Oberlappen.

Die atelectatiscken, rein bindegewebigen Bezirke besitzen geringe Ausdehnung. In Menge und Vertheilung stimmt das Pigment mit dem des vorigen Versuches überein. Ein Unterschied gegenüber diesem tritt aber in der Grösse der einzelnen Körner hervor: In den Heerden und Gruppen überwiegen noch auffallender die kleinen Elemente und treten häuffig als feinste, fast staubartige Körnchen auf. Zugleich ist in vielen die Farbe eine andere geworden: Bei schwacher Vergrösserung hat der Heerd als Ganzes ein dunkles, schwärzliches Ausseben, und bei stärkerer zeigen viele seiner Bestandtheile nicht den lebhaften, kupferrothen Ton, sondern ein mehr schmutziges Braun obne starken Glanz; eine rein schwarze Fürbung konnte ich nirgends entdecken. Diese Erscheinung betrifft ebensowohl die grossen, wie die kleineren Formen. Auch in solchen Heerden indessen finden sich noch Körnchen von derselben reinen rotbbraunen Farbe, wie sie in den letzten Versuchen vorherrschend auftrat, und manche setzen sicb nur aus solchen zusammen.

Die Eisenreaction ist eher etwas ausgiebiger, als in dem 25 wöchentichen Versuch; wenn auch die tiefblau werdenden Körner sehr spärlich sind, so ist doch die Neigung, wenigstens einen bläulichen oder grünen Anflug anzunehmen, verbreiteter, als in jenem, und die Zahl der der. Reaction vollständig widerstehenden Körner geringer. 
Es wurde schon darauf hingewiesen, dass bei meinen Versuchen entgegengesetzt denen von Fleiner das aspirirte Blut eine äusserst geringe Neigung zeigt, in die Lymphwege überzutreten. Dies spricht sich nicht nur darin aus, dass die Bronchialdrüsen in der überwiegenden Mehrzahl der Fälle vollständig frei von Blutkörperchen bezw. ihren Umwandelungsproducten waren, sondern auch in der Vertheilung derselben im Lungengewebe selbst. In den frühsten Stadien fanden sich zwar bisweilen innerhalb der mit Blutkörperchen am reichlichsten vollgestopften Alveolengruppen auch die Septen derart von solchen durchsetzt, dass sie nur noch an den reihenförmig angeordneten Capillarwandkernen kenntlich waren; in den meisten Fällen dagegen war das Lungengewebe selbst unbetheiligt geblieben. Auch die eigentliche Pigmentumwandelung spielte sich in der Hauptsache im Lumen der Alveolen ab. Einen Uebertritt in die interalveolären Bindegewebssepten und von da aus längs der Lymphbahnen in die lymphatischen Knötchen konnte ich erst in den späteren Perioden beobachten und auch dann nur in beschränktem Maasse. Eine grosse Zahl der pulmonalen Lymphknötchen blieb bis zum Ende meiner Versuche vollständig frei von Einlagerungen.

Gegenüber der Virchow'schen ${ }^{1}$ ) Ansicht, dass der grösste Theil des körnigen Pigmentes ebenso wie das krystallinische durch Verdichtung des diffundirten Hämoglobins entstehe, ging von Langhans ${ }^{2}$ ) die Lehre aus, dass die körnige Form nur aus den rothen Blutkörperchen direct durch Schrumpfung und Farbenwechsel hervorgehe, und dass sich dieser Prozess ausschliesslich im Innern contractiler Zellen abspiele.

Bei der Versuchsanordnung, deren ich mich bediente, war an der Stelle, wo das aspirirte Blut zunächst sich ablagerte, reichliches zelliges Material vorhanden. Wie die Inhalationsexperimente von $\mathrm{Knauff}^{3}$ ), Ruppert ) und besonders von $\mathrm{J}$.

1) Virchow, Die pathologischen Pigmente. Dieses Archiv Bd. 1. 1847.

2) Langhans, Beobachtungen über Resorption der Extravasate und Pigmentbildung in denselben. Dieses Archiv Bd.49. 1870.

3) K na uff, Uas Pigment der Respirationsorgane. Dies. Arch. Bd. 39.1867.

4) Ruppert, Experimentelle Untersuchungen über Kohlenstaubinbalation. Dieses Archiv Bd. 72. 1878. 
Arnold ${ }^{1}$ ) ergeben haben, sammeln sich in den Alveolen abgestossene Alveolarepithelien und ausgewanderte Leukocyten, welche einen Theil des eingedrungenen Staubes aufnehmen. Nach dem Urtheil von Ruppert und Arnold über die Versuche von Slavjansky ${ }^{2}$, welcher Aufschwemmungen verschiedener Farbstoffe in die Trachea eingoss, ist die Reaction des Lungengewebes nach der Aspiration flüssiger Medien noch stärker, die Auswanderung der Leukocyten eine hochgradigere als bei Einathmung trockenen Staubes. So erklärt es sich, dass ich in fast allen Lungen sehr reichliche Zellen in den Alveolen traf, bisweilen geradezu das Bild einer katarrhalischen Pneumonie fand. Diese Zellen betheiligten sich an der Pigmentbildung in ausgedehntem Maasse dadurch, dass sie einen grossen Theil der rothen Blutkörperchen in ihr Protoplasma aufnahmen. Dennoch gewann ich den Eindruck, dass dieser Einschluss in contractile Elemente nicht ein Desiderat für die weitere Entwickelung ist, sondern dass auch eine freie Pigmentbildung möglich ist. In allen Stadien des Prozesses begegnete ich rothen Blutkörperchen bezw. ihren Umwandlungsproducten, wenn auch in relativ geringer Zahl, neben den Zellen liegend im gleichen Zustande, wie die eingeschlossenen, und zwar meist vereinzelt, nicht zu Gruppen geordnet und ohne eine Umgebung von Detritus, welche auf vorhergegangenen Zerfall ihres Trägers hingedeutet hätte; ob äberhaupt aus einer zu Grunde gehenden Zelle körniges Pigment frei werden kann, scheint mir zweifelhaft; wenigstens bietet sich häufig Gelegenheit, zu beobachten, wie das absterbende Protoplasma zum Lösungsmittel für das Pigment wird, so dass an die Stelle der Körner eine diffuse Färbung tritt, welche schliesslich mit der Zelle verschwindet. Auch W. Müller ${ }^{3}$ ) zweifelt daran, dass die contractilen Zellen das Privileg als. Pigmentbildner besitzen; er verfolgte systematisch die Metamorphose rother Blutkörperchen, welche aus künstlich erzeugten subcutanen Extravasaten an den Extremitäten in die abhängigen Lymph-

1) J. Arnold, Staubinhalation und Staubmetastase. Leipzig 1885.

2) Slarjansky, Experimentelle Beiträge zur Pneumonoconiosislehre. Dieses Archir Bd. 48. 1869.

3) W. Müller, Untersuchungen über das Verbalten der Lympbdrüsen bei der Resorption von Blutextravasaten. Diss. Göttingen 1879. 
drüsen abgeführt waren. Hier waren also lymphatische Elomente im Ueberschuss zur Stelle, welche die farbigen Körperchen in sich aufnahmen; immerhin sah Müller einen, wenn auch nur beschränkten Theil der letzteren die Umwandlung ausserhalb der Leulsocyten durchlaufen. $0 \mathrm{rth}^{1}$ ) fand in einem Falle von brauner Induration der Lungen ausser den im Lungengewebe an Zellen gebunden oder freiliegenden braunen Körnem in grösseren Gefässen und besonders in Capillaren förmliche Pigmentthromben, welche das Lumen oft vollständig verlegten. Er lässt diese direct aus den in den Gefässen zur Ruhe gekommenen rothen Blutkörperchen entstanden sein und. erkennt ausdrücklich die Möglichkeit einer Pigmentbildung ohne Vermittlung contractiler Zellen an.

Nach Langhans' Ansicht geht ein rothes Blutkörperchen, nachdem es in den Leukocyten aufgenommen ist, durch Veränderung seiner Farbe und Schrumpfung in ein Pigmentkorn, oder unter gleichzeitiger Zertheilung in mehrere dersolben über. Das was den „blutkörperchenhaltigen Zellen" ibren Namen verleiht, sind Gebilde, welche den rothen Blutkörpern vollständig gleichen können, wenn auch die Scheibenform, welche Langhans im lebenden Präparat bisweilen noch erkannte, im gehärteten kaum einmal deutlich hervortritt. An der Mehrzahl von ihnen aber fallen Variationen der Grösse auf, welche dem circulirenden Blute fremd sind; im letateren schwankt der Umfang der farbigen Elemente nur in engen Grenzen. Diese Differenzen, welche ebenso wie die eingeschlossenen, auch die freiliegenden "Blutkörperchen“ betreffen, traten in den von dem ersten Tag nach der Aspiration stammenden Präparaten noch in beschränktem Maasse auf, die überwiegende Menge von jenen unterschied sich nicht vom Inhalt der Gefässe. Nach 2-3 Tagen aber war das Bild ein völlig anderes: Es finden sich eosingefärbte Kugeln in allen Grössenverhältnissen; die meisten bleiben hinter dem nolmalen Volumen der Scheiben zurück, nehmen bisweilen nur den ungefähr vierten Theil desselben ein; seltener überschreiten sie den gewöhnlichen Unfang, bis zum Doppelten desselben heranreichend.

1) Orth, Zur Kenntniss der bramnen Induration der Lunge. Dieses Archiv Bd. 58. 1873. 
Gleichzeitig sind sie vor den in den Gefässen liegenden Blutkörperchen durch ihren Glanz und ihre Färbbarkeit ausgezeichnet: Während diese sich mit Eosin gelblichroth tingiren und mässigen Glanz besitzen, nehmen jene eine dunklere Rosafarbe an und sind stärker lichtbrechend. Hier und da traf ich auch blasse, ungefärbte Gebilde von dem Umfang einer Blutscheibe, innerhalb deren solche glänzende rothe Kügelchen lagen. Die an den lebenden Froschpräparaten gesammelten Erfahrungen führen wich zu der Vermuthung, dass das, was als rothe Blutkörperchen imponirt, in der grossen Mehrzahl nur den Farbstoff derselben repräsentirt, welcher aus dem Stroma ausgetreten ist und sich, wie in den Froschversuchen, tropfenförmig erhalten hat, und dass diese Hämoglobintropfen das wesentliche Substrat des Pigmentes abgeben, mögen sie in Zellen eintreten, oder frei bleiben. Langhans erwähnt das Vorkommen kleiner Kugeln, welche er am ersten Versuchstag vorfand, ohne ihre Entstehung beobachten zu können, and welche er als Hämoglobinkugeln bezeichnet; für die Folge schreibt er ihnen keine wichtige Rolle beim Ablauf des Prozesses zu. Im Allgemeinen herrscht bei den Hämoglobintropfen die Tendenz zur Verkleinerung vor, während ein Zusammenfluss mehrerer zu grösseren Gebilden seltener stattfindet

Vielleicht ist es auch an den alternden Scheiben des circulirenden Blutes dieser Act der Zerlegung in Hämoglobin und Stroma, welcher das Signal zur Entstehung der "blutkörperchenhaltigen Zellen" inverhalb der Organe mit verlangsamter Circulation giebt. Quincke sucht dasselbe darin, dass die Blutscheiben allmählich starrer werden und leichter an den Pseudopodien haften, als die schmiegsameren jugendlichen.

Die weitere Umwandlung besteht im Uebergang der Farbe der Hämoglobintropfen in ein helles Gelb unter Verlust der Tinctionsfähigkeit mit Eosin und unter Zunahme des Glanzes. Nicht selten tritt gleichzeitig eine Formveränderung derart auf, dass die erst kreisrunde Peripherie unregelmässig eckig wird. Der Pigmentbildungsprozess setzt offenbar nicht an allen rothen Blutkörperchen gleichzeitig, sofort nach der Aspiration ein. Nie habe ich ein Präparat gefunden, in welchem nur ein Stadium desselben vertreten war: Am 3.-4. Tage traf ich zuerst fertige Pigmentkörner, aber nur in spärlicher Zahl; neben ihnen lagen 
viele Blutkörper, welche den Eindruck vollständiger Unversehrtheit machen und andere Gebilde von kugeliger Form und verschiedenem Umfang, welche ich für Hämoglobintropfen halte. Von Tag zu Tag nimmt die Zahl der letzteren ab und mehrt sich die Menge der gelben glänzenden Körner und mit dem Beginne der zweiten Woche nach der Aspiration hat die Metamorphose durchweg ihr Ende erreicht.

Einer Erwähnung bedarf noch die diffuse Färbung der Zellen, welche ich einige Mal in den ersten Tagen nach der Blutaspiration beobachtete. Wo sie in meinen Präparaten auftrat, war sie in der Regel so hell, dass ich erst, nachdem sie durch die Reaction in Blau übergeführt war, auf sie aufmerksam wurde. Nie traf ich sie in grösserer Ausdehnung, noch weniger als constante Erscheinung, so dass sie die Bedeutung eines für die weitere Entwickelung wichtigen Stadiums nicht beanspruchen kann. Sie fand sich nur in Fällen, in welchen ein reichlicherer Untergang von Zellen stattzufinden schien, wo die Desquamation der Alveolarepithelien eineu hohen Grad erreicht hatte und bisweilen mit Exsudation einherging, so dass das Bild der katarrhalischen Pneumonie entstand; auch die Zellen selbst, deren Protoplasma ganz oder zum Theil diffus gefärbt war, unterschieden sich meist von ihren Nachbarn, welche das Pigment in körniger Form enthielten, durch ihren bedeutenderen Unfang, ihr gequollenes Aussehen, die mangelhafte oder fehlende Kernfärbung. Es schien mir danach die diffuse Pigmentirung nur der Ausdruck des Unterganges der Zellen żu sein und aus Körnern zu entstehen, welche beim Absterben ihrer Träger sich auflösten, wie es Langhans regelmässig als Endstadium des Prozesses dem vollständigen Schwunde des Pigmentes vorausgehen sah.

Für die Einleitung der Pigmentmetamorphose der rothen Blutkörperchen möchte ich also die Trennung des Stroma vom Hämoglobin halten, welches letztere in ungelöster Form direct in die gelben Körner übergeht, gleichviel, ob es von contractilen Zellen aufgenommen wird oder nicht.

Die chemische Ausbildung hält mit der morphologischen ziemlich gleichen Schritt. Schon am 4. Tage nach der Aspiration bläute sich unter der Einwirkung des Ferrocyankali-Salz- 
säuregemisches ein Theil des noch spärlichen Pigmentes, der andere indessen widerstand der Reaction. Da nicht alle aspirirten rothen Blutkörperchen sofort der Metamorphose anheimfallen, also täglieh ein neuer Nachschub von jungem Pigment erfolgt, so dauert dieses Nebeneinanderauftreten von reagirenden und nichtreagirenden Köruern eine Zeit lang fort, so dass erst einige 'Tage, nachdem der letzte Rest der eingeführten Blutkörperchen aufgezehrt ist, an allem gebildeten Pigment auch die chemische Metamorphose zum Ziele geführt worden und durchweg Hämosiderin entstanden ist. In der Regel fiel dieser Zeitpunkt auf den Anfang der 3 . Woche.

Es geht daraus hervor, dass zwischen der morphologischen und der chemischen Vollendung ein allerdings nur sehr kurzer Zeitraum liegt, dass es ein unter denselben Bedingungen, wie das Hämosiderin, entstandenes Pigment von derselben äusseren Gestaltung, wio dieses giebt, welches die mikrochemische Eisenreaction verweigert. Am einzelnen Korn ist der Uebergang der Verbindung, in welcher der Eisengehalt noch latent ist, zu der, in welcher er sich mikrochemisch documentirt, nicht immer ein schroffer, plötzlicher: Zuerst tritt nur ein kleiner Theil des darin befindlichen Eisens in den nachweisbaren Zustand ein und seine Bläuung mischt sich mit der gelb bleibenden Farbe des übrigen zu einem grülichen $\mathrm{T} o n$; je mehr die Menge des reagirenden zunimmt, desto mehr neigt sich das Grün der blauen Nuance zu und auf dem Höhestadium erscheint das Korn in eine Kugel von gesättigter, tiefblauer Farbe verwandelt, so dass es den Eindruck macht, als bestehe es nur aus einer anorganischen Verbindung, welche in reines Berlinerblau übergeführt wird. In Hindenlang's ${ }^{1}$ ) Falle von Morbus maculosus mit reichlicher Pigmentablagerung in inneren Organen fand $\mathrm{Kunkel}{ }^{2}$ ) durch chemische Analyse, dass die braunen Schollen aus reinem Eisenoxyd bestanden. Die weiteren Schicksale des Pigmentes in meinen Versuchen jedoch verbieten die Verallgemeinerung dieses

1) Hindenlang, Pigmentinfiltration von Lymphdrüsen und anderen Organen in einem Fall von Morbus maculosus Werlhofii. Dieses Archiv Bd. 79. 1880 .

2) Kunkel, Notiz zu dem Aufsatze des Herrn Dr. Hindenlang. Dieses Archiv Bd. 81. 1880. 
Resultates und führen mich zu der Ueberzeugung, dass auch die tiefblauen Körner eine organische Materie enthalten.

Ueber die weitere Geschichte des Hämosiderins ist wenig bekaunt; man nimmt an, dass dasselbe, nachdem es ein gewisses Alter erreicht hat, wieder vollständig verschwindet. Langhans beobachtete, dass die groben Körner allmählich in feinere zerfallen, die sich auflösen und das Protoplasma diffus färben als Vorbereitung für ihre völlige Resorption, und dass bei kleinen Extravasaten schon 3-4 Wochen nach ihrer Entstebung jeder Rest der Pigmentirung verschwunden ist. In Sommerbrodt's Versuchen waren 5 Wochen nach der Injection von Blut in die Lungen die Alveolen wieder von den Residuen desselben befreit.

Meine Versuche gestatteten eine längere Beobachtung. Das älteste Kaninchen, welches 28 Wochen nach der Aspiration lebte, enthielt in seinen Langen Pigment, dessen Menge ich nicht geringer schätzte, als bei den in früheren Perioden getödteten. Bezüglich der äusseren Erscheinung sind die weiteren Veränderungen unbedeutend und vollziehen sich nur sehr langsam. Zu der zuerst hell-, fast strohgelben Farbe kommt eine Beimischung von Braun, welche allmählich mehr in den Vordergrund tritt, so dass den Körnern erst ein goldgelber und gelbbrauner und schliesslich ein mehr rothbraunel kupferähnlicher Farbenton verliehen wird, welcher sich für die Folge meist constant erhält. Doch kam bisweilen am prägnantesten in dem ältesten 28 wöchentlichen Versuche, noch eine neue Nuance hinzu, eine schwärzliche Verfärbung, welche das Roth in den Hintergrund drängte und den Körnern ein dunkles, schmutzig braunes, weniger glänzendes Aussehen gab. Auch in der Grösse der einzelnen Elemente gehen langsame Veränderungen vor sich: Noch in den spätesten Stadien fand ich Kugeln von ungefähr dem doppelten J)urchmesser eines rothen Blutkörperchens, doch wurde die Zahl derselben mit dem zunehmenden Alter geringer, während die kleinen Formen an Menge wuchsen, so dass allem Anschein nach ein Zerfall der groben Körner in feinere stattfand. Zu einer terminalen diffusen Imbibition mit Pigment ist es in keinem meiner Experimente gekommen.

Das Hauptgewicht in dem Schicksale des Hämosiderins ruht auf der sich allmählich vollziehenden chemischen Umwandlung. 
Das Höhestadium der Eisenreaction, in welchem ein Korn wie das andere gesättigt blau gefärbt wird, dauert zunächst an. Nach Verlauf einiger Wochen aber - ich bemerkte die ersten Andeutangen 9 Woohen nach der Aspiration - stellen sich Differenzen in dem Grad des Farbenwechsels ein, und es kommen dieselben Nuancen zum Vorschein, welche das junge Pigment im Verlaufe seiner Entwickelung anfwies: Nur ein Theil der Körner bleibt in vollem Maasse empfänglich und wird tiefblau; bei einem anderen blickt wieder die gelbbraune oder braunrothe Grundfarbe hervor und mischt sich mit dem Blau $\mathrm{zu}$ einem mehr oder weniger intensivem grünlichen Ton; einige Körner endlich lehnen die Reaction vollständig ab. Je älter das Pigment wird, desto mehr nimmt die Zahl der schwach oder nicht reagirenden Körner zu, desto spärlicher werden die, welche sich intensiv verfärben. Die niederste Stufe des Farbenwechsels, der discrete bläuliche Anflug, ist am einzelnen Pigmentkorn oft vicht mehr wahrzunehmen, und nur aus dem Schimmer, den der Heerd in toto bei schwacher Vergrösserung zeigt, geht hervor, dass noch eine Spur mikrochemisch nachweisbaren Eisens vorhanden ist. Schliesslich kann auch dieser schwinden; fast regelmässig traf ich in den den späten Versuchsperioden angehörigen Lungen Pigmentnester, in denen nicht nur einzelne, sondern sämmtliche Elemente sich gegen das Ferrocyankali-Salzsäuregemisch absolut ablehnend verhielten. Bis zu dem Stadium, in welchen überhaupt keins der vorhandenen Körner mehr Spuren des Farbenwechsels zeigten, haben meine Experimente nicht geführt.

Das Stadium der Eisenreaction ist also nicht von Bestand; es repräsentirt nur eine Stufe in der fortwährend weiterschreitenden Entwickelung des scheinbar unveränderlichen körnigen Pigmentes und verschwindet mit dem zunehmenden Alter. Es giebt ein hämatogenes, körniges Pigment, welches von gleicher Beschaffenheit und unter gleichen Bedingungen, wie das Hämosiderin entstauden, kein mikcochemisch nachweisbares Eisen enthält.

Die Neumann'sche Theorie, dass die Lebensfähigkeit des Gewebes, in welches die rothen Blutkörperchen extravasiren, 
bestimmend ist für die Ausbildung des eisenfreien Hämatoidins oder des Hämosiderins, wird durch die Resultate meiner Versuche nicht angegriffen. Wohl aber verbieten dieselben den Schluss aus dem mangelnden Eisengebalt des Pigmentes auf die Lebensfähigkeit des Gewebes, in welchem es entstanden ist.

Jetzt komme ich noch einmal kurz auf die in der Einleitung angefïhrten Präparate zurück, in denen offenbar durch den gleichen Bildungsmodus entstandenes Pigment sich mikrochemisch verschieden verhielt. Gerade in den Fällen wurde die Differenz am auffalligsten gefunden, wo das vorhandene Pigment nicht aus einem einmaligen Extravasate entstanden war, sondern dauernd, - wie in Milz, Leber und Knochenmark normaler Weise, oder in einzelnen Attaken durch mehrmals sich wiederholende Hämorrhagien beues Material zugeführt wurde. In dem Ovarium, dessen ich Erwähnung that, kano die Intensitat der Eisenreaction geradeza als Kriterium bei der Bestimmung der Altersunterschiede der einzelnen Follikelnarben benutzt werden.

Im Folgenden möchte ich versuchen, die Thatsache, dass das Stadium der Eisenreaction vergänglich ist, für die Feststellung der Herkunft gewisser Pigmente zu verwerthen.

Zur Bestimmung des Charakters vieler normaler und pathologischer Pigmente ist die Eisenreaction befragt worden. Aus den Stimmen fast aller Forscher geht die Ueberzeugung hervor, dass dieselbe entscheidend sei, dass ein körniges Pigment, wenn es vom Blutfarbstoff abstamme, mikrochemisch nachweisbares Eisen besitzen müsse, und nur in diesem Falle besitzen könne; nur bei Nothnagel') fand ich Zweifel an der Beweiskraft der Reaction ausgesprochen; er hält es für möglich, dass hämatogene Farbstoffkörner das Eisen in einer der Berlinerblaureaction unzugänglichen Verbindung einschliessen; und ebenso bei $O p p e n-$ heimer ${ }^{2}$ ), welcher darauf hingeführt wurde, dadurch, dass in den Pigment eines melanotischen Sarcoms durch die chemische

1) Nothnagel, Zur Pathologie des Morbus Addison. Zeitschr. f. klin. Hed. Bd. IX. 1885.

2) Oppenbeimer, Beiträge zur Lehre von der Pigmentbildung in melanotischen Geschwülsten. Dieses Archiv Bd. 106. 1886. 
Analyse Eisengehalt constatirt wurde, welcher sich bei mikrochemischer Untersuchung verleugnete. Perls ${ }^{1}$ ) selbst unternahm mittelst seiner Methode eine ausführliche Untersuchung der verschiedensten Farbstoffe des Körpers, welche bald darauf von Kulenkampff $f^{2}$ ) wiederholt und ausgedehnt wurde. Beide fanden die Reaction eintreten in allen den Fällen, wo das Pigment sicher durch Hämorrhagien entstanden war, z. B. bei der braunen Induration der Lungen, hämorrhagischen Infarcten, Pachymeningitis haemorrhagica; erfolglos blieb sie an den Präparaten, für welche man von jeher metabolischen Ursprung des Pigmentes angenommen hatte, weil in den histologischen Verhältnissen keine Beziehungen zu den Blutgefässen und ihrem Inhalt angedeutet liegen, z. B. der normalen Chorioidea, den Haaren, dem Rete Malpighii, den melanotischen Tumoren. Die Resultate dieser beiden Autoren sind zwar im Allgemeinen von den späteren Forschern bestätigt worden; doch stellten sich oft in Einzelfällen derselben Krankheit verschiedene Befunde heraus: So sah Perls bei Morbus Addisonii das Pigment des Corium sich bläuen, das des Rete Malpighii nicht; Kulenkampff traf im subcutanen Gewebe einzelne Körnchen, deren einige die Reaction eingingen, während die des Epithels unempfänglich blieben; Nothnagel erhielt vollständig negatives Resultat.

Den inconstantesten Befund bezüglich des Eisengehaltes hat die Untersuchung der melanotischen Geschwülste zu Tage gefördert, und auf die mannichfaltigen objectiven Grundlagen sind die verschiedensten Urtheile über den hämatogenen oder autochthonen Charakter gebaut worden. Wie erwähnt, gelang Perls und Kulenkámpff die Eisenreaction nie; ebenso verzeichnen Oppenheimer und Decking ${ }^{3}$ ) ausdrücklich negatives Ergebniss, ersterer bei einem Melanosarcom des Gehirns, letzterer bei einem solchen der Haut. Glücklicher war Hirschberg ${ }^{4}$ ), welcher in einem präcornealen "Melanocarcinom" das Pigment

1) Perls, a. a. 0 .

2) Kulenkampff, Ueber den Nachweis von Eisen in gewissen Pigmenten. Diss. Würzburg 1868 .

3) Decking, Ueber Melanosarcoma. Diss. Würzburg 1887.

4) Hirscbberg, Ein Fall von Melanocarcinoma praecorneale. Dieses Archiv Bd. 51. 1870. 
bei der Perls'schen Reaction sich bläuen sah. Vossius') untersuchte 10 melanotische Tumoren des Auges und fand in 6 Fällen den Farbenwechsel eintreten, in den 4 übrigen nicht. Nicht weniger gehen die Resultate auseinander, welche die chemische Analyse des Melanins der Geschwülste ergeben hat: Virchow ${ }^{2}$ ) liess einen melanotischen Unterleibstumor, die Netastase eines melanotischen "Krebses" des Auges untersuchen, wobei kein Eisen gefunden wurde. E is el $t^{3}$ ) constatirte selbst in einem Falle Eisen and führt 2 weitere von Lassaigne und Barruel mit demselben Erfolg unternommene Analysen an. Ein von Dressler ${ }^{4}$ ) untersuchter metastatischer Lebertumor enthielt in der Asche 21,5 pCt. Eisen. In neuerer Zeit stellten Berdez und Nencki ${ }^{5}$ ) den Farbstoff aus der Lebermetastase eines melanotischen Hautsarcoms vom Menschen und aus mehreren Sarcomknoten eines Schimmels dar und fanden sehr hohen Schwefelgehalt, aber kein Eisen; in dem erwähnten Falle von Oppen. heimer wies Nenoki Eisen nach. Mörner ${ }^{6}$ ) kritisirt die von Berdez und Nencki zur Isolirung des Pigmentes angewandte Methode und glaubt, dass dieselbe das Eisen vor der Analyse aus demselben ausgetrieben hat; er selbst stellte solches aus der Asche eines metastasenreichen Hautsarcoms dar.

Beide Ansichten, welche sich auf diese chemischen Untersuchungen gegründet haben, die von dem autochthonen und die von dem hämatogenen Ursprung des Melanins, haben ihre Anhänger gefunden und sind durch weitere Zusätze von diesen gestützt worden: v. Recklinghausen ${ }^{7}$ ), welcher die Abstammung vom Blutfarbstoff bezweifelt, macht darauf aufmerksam, dass

') Vossius, Mikrochemische Untersuchungen über den Ursprung des Pigmentes in melanot. Tumoren des Auges. Graefe's Archiv Bd. 31. 1885.

2) Virehow, Die pathol. Pigmente. Dieses Archiv Bd.1. S. 477. 1847.

3) Eiselt, Ueber Pigmentkrebs. Prager Vierteljahrschr. Bd. 76. 1862.

4) Dressler, Untersuchung des Farbstoffs eines melanot. Leberkreoses. Ibidem Bd. 88. 1865.

5) Berdez u. Nencki, Ueber den Farbstoff melanot. Tumoren. Arch. f. exper. Path. u. Pharmak. Bd.20. 1886.

6) Mörner, Zur Kenntniss von d. Farbstoffen d. melan. Geschwälste. Zeitsehr, f. physiol. Chomie. Bd. 11. 1887.

7) v. Recklinghausen, Allgern. Pathologie. S. 441 u. 443. 1883. 
das Melanin sich durch seine Farbe wesentlich von den Hämoglobinderivaten unterscheide, dass ihm der rothbraune oder goldgelbe Ton der letzteren fehle, und die Neigung zum Schwarzbraun und zur Sepiafarbe vorherrsche. Desgleichen betonen Cornil und Ranvier ${ }^{1}$ ), dass das normale Pigment der Chorioidea und Iris, ebenso wie das unter pathologischen Verhältnissen entstandene von Anfang an schwarz erscheine, ohne die gelben und rothen $Z$ wischenstufen durchlaufen zu haben, und dass man es als ein besonderes, vom Blutfarbstoff unabhängiges Product der Zellen ansehen müsse. Unbekümmert um die chemischen Thatsachen fassen Langhans ${ }^{2}$ ) und Gussenbauer ${ }^{3}$ ) nur die feinen anatomischen Verhältnisse in's Auge. Beide legen Gewicht auf die vorherrschende Pigmentirung der den Gefässen benachbarten Zellen gegenüber der geringen Färbung der ferneren Bezirke und sehen hierin ein Kriterium für die Herkunft des Pigmentes aus dem Blutfarbstoff; sie differiren nur in der Ansicht über die Form, in welcher das Hämoglobin geboten wird, Langhans lässt sich die Metamorphose an den unveränderten rothen Blutkörperchen vollziehen, Gussenbauer nimmt eine Iiffusion des Blutfarbstoffs und darauf folgende körnige Ausfällung an. Ebenfalls nur auf histologische Thatsachen gestützt urtheilen Hirschberg und Birnbacher ${ }^{4}$ ); sie trafen in einem Melanosarcom des Auges ausser im Geschwulstgewebe auch innerhalb der Gefässe fertiges Pigment und alle Uebergangsstufen von den rothen Blutkörperchen zu diesem und ausserdem feine Körnchen im Protoplasma der Gefässendothelien. In einem Falle von epibulbärem Sarcom erhob Birnbacher ${ }^{5}$ ) denselben Befund.

In einem Punkte stimmen alle Autoren überein, dass nehmlich das Pigment local innerhalb der melanotischen Tumoren gebildet wird.

1) Cornil et Ranvier, Manuel d'Histologie pathol. 1881. Tome I. p. 82 et 170 .

3) Langhans, Ein Fall von Melanom der Cornea. Dieses Archiv Bd. 49. 1870 .

3) Gussenbaner, Ueber die Pigmentbild. in melanot. Sarcomen und einfachen Melanomen der Haut. Dieses Archiv Bd.63. 1875.

4) Hirschberg u. Birnbacher, Sarcoma melanot. corp. cil. et chorioideae. Centralbl. f. Angenbeilk. Bd. 8. 1884. S. 10.

5) Birnbacher, Ueber die Pigmentirung melanot. Sarcome. Ibidem S. 38. 
Im Folgenden will ich äber einige Fälle von Melanosarcomen berichten, welche theils unversebrt zur Verfügung standen, theils in Würfel zerschnitten conservirt waren, so dass sich die topographischen Verhältnisse nicht immer mehr feststellen liessen.

1. Fall. Anf der chirurgischen Klinik des Hern Geh.-R. Ozerny wurde bei einem 67jährigen Manne ein Melanosarcom der Glutäalgegend exstirpirt, welches sich im Lanfe eines Jahres entwickelt hatte.

Die Haut zieht über den fanstgrossen Tumor ranchgrau verfärbt, sonst meist unverändert hinweg und ist nur an wenigen Stellen von pilzförmigen Wucherungen durchbrochen. Der untere Theil der Geschwulst ist in das subcutane Fettgewebe eingesenkt. Auf der Schnittfäche ist der Grad der Pigmentirung wecbselnd, am dunkelsten, rein schwarz gefärbt erscheint die tiefstgelegene Hälfte. Schon makroskopisch zeigt sich, dass das umgebende Fettgewebe in der dem Tumor benachbarten Zone an der Verfärbung theilnimmt, besonders die Bindegewebszüge, welche die einzelnen Fettläppchen von einander trennen, treten als dunkle Streifon hervor. Dem mikroskopischen Verhalten nacb gehört der Tumor den Angiosarcomen an, zeigt an den meisten Stellen deutlich ausgesprochenen alveolären Typus; seine Elemente sind theils runde, theils mehr spindelige Zellen. Durch die Gesehwulst ziehen vielfach mehr oder weniger breite Bindege webssepten, innerhalb deren die grösseren Gefässe verlanfen. Im Tumor selbst sind diese Septen die Hauptträger des Pigmentes; sie enthalten es in viel reicblicherer Menge, als das eigentliche Sarcomgewebe. Es tritt in ihnen in Form länglicher, parallel verlaufender, den Lymphspalten entsprechender Züge auf, welche entweder aus frei neben einander liegenden Körnern. zusammengesetzt werden, oder durch Aneinanderreihen maulbeerförmiger Gruppen von solchen entstehen. Diese Gruppen trifft man auch vielfach vereinzelt; so sehr sie ihrer Form, Grösse und scharfen Begrenzung nach den Eindruck von pigmentbeladenen Zellen machen, so gelingt es doch niemals, die Kriterien einer solchen, besonders einen Kern, zn sehen. Viele Körner lieg'en isolirt, zerstreut in Gewebe. Die fixen Zellen der Bindegewebszüge nehmen an der Pigmentirung Theil und enthalten bald nur wenige Körner, bald sind sie mit solchen vollgestopft. Am reichlichsten ist die Anhäufung in der nächsten Umgebung der bleinen Gefässe und in den Adventitialscheiden der letzteren selbst. Bei den dünnwandigen enthalten nicht selten die Endothelien Körner und hier und da liegen solche sogar im Gefässlumen frei. Das eigentliche Sarcomgewebe fübrt am meisten Pigment in den Bezirken, welche an die beschriebenen Bindegewebssepten angrenzen, und in der nächsten Nähe der die einzelnen Alveolen von einander trennenden Gefässe. Wo die alveoläre Architectur fehlt und die Sarcomzellen auf grössere Strecken diffus angeordnet sind, ist stets die Umgebung der Gefässe die bevorzugte Ablagerungsstelle. Die Körner liegen sowohl in spindelförmigen und runden Sarcomzellen, als in den Räumen $z$ wischen diesen, oft in reihenförmiger Anordnung; ausserdem treten anch hier wieder häufig die grösseren aus Kür- 
nern zusammengesetzten braunen Klumpen auf und liegen, wie es scheint, in Lücken $z$ wischen den Sarcomzellen, obne dass sich entscheiden lässt, $o b$ sie übermässig gefüllten und deshalb voluminöser gewordenen Geschwulstelementen entsprechen, oder den in den Bindegewebszügen bescbriebenen maubeerförmigen Gebilden gleichstehen. Ijiffuse Braunfärbung ist selten und erstreckt sich stets aur auf wenige benacbbarte Zellen. Die schon inakroskopisch kenntliche Pigmentirung in der Umgebung des Tumors ist mibroskopisch auf ziernlich weite Entfernung von der Grenze desselben zu verfolgen. Hier sind es vor Allem wieder die Lymphspalten, besonders die perivasculären, welche die Körner theils frei, theils in Zellen mit deutlichem Kern enthalten, sodass wiederum lange braune Züge formirt werden. Weiterhin nehmen Theil die Gefässendothelien und die fixen Bindegewebs-, besonders die Fettzellen, innerbalb deren sicb der Farbstoff um den Kern herum anbäuft. Vielfach reicht das Sarcomgewebe bis an die Epidermis, an anderen Stellen sind die Cutispapillen intact und erst die tieferen Schichten sarcomatös. Auch diese Cutispapillen entbalten Pigment, theils frei, theils in Zejlen, besonders verzweigten; gleicbueitig ist auch die Epidermis darüber verfärbt; einzelne Körner liegen in den Epithelien, oft scheinen sie nur frei 7wischen diesen in reibenförmiger Anordnung sich aufzuhalten, oder im Innern verzweigter Zellen. - Die einzelnen Farbstoffkörner besitzen runde oder unregelmässig eckige Form. Ihr Umfang variirt ausserordentlich: Die grössten nehmen ungefäbr den 4fachen Raum eines rotben Blutkörperchens ein, und von diesen finden sich alle Uebergangsstufen bis herab zu feinsten Kügelchen. Die Farbe ist ziemlich übereinstimmend ein Rothbraun, entweder rein, oder etwas schmutzig, der Glanz ein intensiver.

Von den verschiedensten Partien der Geschwulst wurden Schnitte zur Eisenreaction verwendet. Die dunkelsten Stellen erwiesen sich nur sebr wenig ergiehig; indessen waren es doch einzelne Körnchen, welche sich bläuten, baid isolirt liegende, bald mit anderen, unempfänglichen zu einer Gruppe vereinigte; innerhalb des eigentlichen Geschwulstgewebes traf ich hier nie die Reaction, nur in den Bindegenebszügen zwischen diesen. Das dankbarste Feld findet die Reaction in den peripherischen, offenbar jüngsten Abschnitten des Tumors, z. B. an einem kleinen Sarcomknoten, weleher im Fettgewebe eingebettet dicht neben der Hauptmasse liegt. In der Umgebung desselben sind die Lyropspalten und die fixen Bindegewebszellen mit Pigment erfullt; von diesem wird ein grosser Theil durch die Reaction verändert, und zwar tritt der Farbenwecbsel in allen den Abstufungen voin gesättigten Blau an auf, welche bei früherer Gelegenheit beschrieben wurden. Das Gleiche gilt von dem dem Sarcomknoten selbst angehörigen Farbstoff; derselbe reagirt in ausgiebigem Grade, und zwar ist die Bläung unablängig von der Lagerung, sie betrifft sowobl Körner, welche frei liegen, als solche, welche in Sarcomzellen, oft mit unveränderten zusammen, eingeschlosken sind. Diese empfänglichen Elemente sind son den nicht reagirenden weder durch Grösse noch Farbe vor der Reaction untersehieden. Der stärkste und ausgebreitetste Farbenwechsel findet sich au dem einen Pol des länglichen 
Knotens, in dessen Umgebung auch die Lymphspalten am reichlichsten Hämosiderin enthalten.

II. Fall. Bei einem 4tjährigen Manne waren unter einem seit vielen Jabren bestehendeu Nävus der Stirn rasch mebrere Knoten entstanden; 4 Wochen nach ihrem ersten Auftreten wurden sie in der Klinik des Herrn Geh.-Ratb Czerny mitsammt dem kleinhandtellergrossen, schwärzlicbgrau verfärbten Hautstück exstirpirt. Die Oberfläche des letyteren ist glatt, die Geschwulstknoten, deren grösster ungefähr den Umfang einer Wallnuss besitzt, wölben sich nur über die untere, wunde Fläche vor, Auf den Durchschnitt des Nävus erscheint die Cutis hellgrau, unter ihr zieht sich ein rein schwarzer, dem subcutanen Bindegewebe entsprechender Streifen hin, welcher sie auch von den Geschwulstknoten trennt. Von diesen sind einige weiss, andere im Gavzen rauchgrau verfärbt, bei noch anderen erscheint die Schnittfläche wie geädert, von einem feinen Netz schwarzer Linien durchzogen.

Bei mikroskopischer Untersuchung tritt der Haupttheil des Pigmentes der Haut in Form brauner welliger Linien auf, welche in der Cutis bald parallel verlaufen, bald sich netzförmig verbinden; im subcutanen Gewebe, wo sie noch viel reichlicher sind, verlaufen sie meist zu Büscheln geordnet, zwischen den Fettzellengruppen. Gleicht schon die Gestalt und Anordnung dieser Züge vollkommen der der elastischen Fasern, so kommt hinzu, dass sie sich nicht selten mit solchen, ungefärbten, zu Netzen verflechten, dass bisweilen eine braune Wellenlinie unter plötzlichem Aufhören ibrer Färbung sich in eine farblose fortsetat, welche nach ibrem doppelten Contour und intensiven Glanz zweifellos eine elastische Faser repräsentirt, dass endlich einige der letzteren im ganzen Verlaufe weiss und nur an einzelnen umschriebenen Stellen wie braun gefleckt erscheinen. Das Pigment folgt also den elastischen Fasern, deren Oberfläche es aufliegt; an vielen setzt sich. dieser Farbstoffmantel aus Körnern zusammen, meist von kleinem, seltener von grösserem Umfang: diese letzteren springen gewöhnlich über den glation Contour vor; an anderen Stellen aber gelingt diese Auflösung in Körner auch mit starken Linsen nicht, die Farbe erscheint diffus. Ein weiterer Theil des Pigmentes ist in das Gewebe zwischen den elastischen Fasern und jbren Bündeln eingestreut, bald als isolirte Körner, bald als Gruppen solcher, welche ebenso häufig frei, als im Protoplasma von Zellen liegen; bisweilen ordnen sich die Körner oder ihre Conglomerate zu gestreckten kurzen Zügen zusammen, welche neben den Haarbälgen und Talg- und Schweissdrüsen der Oberfäche zustreben, in den tiefsten Schichten aber, nahe der Grenze der Geschwulstknoten in der Regel dieser parallel verlaufen; bisweilen auch folgen sie dem Verlauf der kleineren Gefässe, in deren Bindegewebsscheide liegend. An den Körnern wiederholen sich alle die Grössenformen, unter denen das hämatogene Pigwent in den Kaninchenversuchen gefunden wurde: Von den feinsten Kügelchen in aufsteigender Reihenfolge bis hinauf $\mathrm{zu}$ Schollen, welche ein rothes Blutkörperchen an Umfang erreichen, oder sogar übertreffen. Die Gestalt ist seltner rund, meist unregel. 


\section{8}

mässig eckig, in der Farbe herseht ein gläuzender, reiner, braunrother Ton vor, bisweilen tritt eine schmutzige Beimischung binzu, welche den Körnein oin sepiaähnliches Aussehen verleiht. - Durch die Sarcomknoten ziehen Bindegewebssepten als Träger der Gefässe; von letzteren aus entwickeln sich die Capillaren, deren netzförmige Verzweigung den alveolären Charakter bedingt. Wanche der Knoten enthalten fast kein Pigment, andere reichliche Mengen. Ueberall prävalirt die Färbung in den Bindegewebsepten und Gefässscheiden über die im eigentlichen Sarcongewebe. Die Gefässlumina sind umgeben von mehr oder weniger vollständigen, braunen Ringen, welche der Adventitia angehören; dieselben setzen sich aus einzelnen Körnern und aus Häufchen von solchen zusammen, welche der Giösse und Gestalt nach oft einer Zelle zu entsprechen scheinen, meist aber Kern und Protoplasmasaum vermissen lassen. Form and Umfang unterseheiden die einzelnen Pigmentelemente der Geschwulst nicht von denen des Nävus; nur die Farbe ist mannichfaltiger, neben dem Rothbraun tritt vielfach ein Goldgelb hervor mit allen Uebergangsstufen zu jenem; der scbwärzliche, schmutzige Ton fehlt vollstündig. Diese Massen begleiten von den kleineren Gefässen an deren Vorzweigungen und dringen mit diesen zwischen die Alveolen ein; wo die Bindegewebsscbeiden fehlen und die Sarcomzellen sich direct von den Endothelien erheben, wird das Pigment spärlicher; es liegt hier zwischen diesen beiden Elementen in Form von einzelnen Körnern und Häufchen solcher, so dass das Lumen zuweilen durch die Vorbuchtung des Endotbels verengt wird. Innerhalb der Geschwulstalveolen fält die Menge des Farbstoffes von den peripherischen Zonen nach dem Centrum zu rasch ab. Fin durchgängig gleiches Verbältniss der Körner zu den Sarcomzellen besteht nicht, ein Theil liegt, jedesmal in grösserer oder kleinerer Zabl, in dieselben eingeschlossen, ein ebenso grosser zwischen ibnen; die kleinen Kügelchen prävaliren hier vor den grösseren Schollen. Von Hämorrhagien oder isolirt ausserhajb der Gefässe liegenden rothen Blutkörperchen ist nichts zu sehen.

Die Eisenreaction ist sehr ausgiebig: In dem alten Nävus bleibt unverändert alles längs der elastischen Fasern sich hinziehende Pigment und von dem übrigen das der Cutis und den oberen Schichten des subcutanen Gewebes angehörige; in den unteren, der Gescbwulst benachbarten Regionen aber tritt Farbenwecbsel ein; und zwar an der Mehrzahl der hier stationiten Körner, nur die geringere Zahl derselben widersteht; gebläute und unveränderte liegen oft in einer und derselben Gruppe. Voa dem dern Tumor selbst angehörigen Pigment bläut sich der weitaus grösste Theil; zu dem unempfänglichen gehören wenige der in den Lymphspalten der Gefässwände und der Bindegewebssepten und die grössere Hälfte der in eigentlichen Sarcomgewebe liegenden Körner. Der Grad der Reaction ist nicht überall der gleiche; obwohl das tiefe gesättigte Blau vorberscht, blickt doch hier und da noch die braune Grundfarbe durch und miseht sich mit dem Blau zu einem helleren oder dunkleren Grün. Von der Grösse der Körner ist die Intensität des Farbenwecbsels unabhängig. 
Die mitgetheilten Beobachtungen können als Prototyp für das gelten, was ich in fast allen untersuchten Melanosarcomen fand, bezüglich der Vertheilung des Pigmentes sowohl, als der Eisenreaction. Die letztere vermisste ich in vereinzelten Fällen, wo mir nur wenig Geschwulstpartien aus den stärkst pigmentirten Stellen zu Gebote standen und die Untersuchung der jüngeren Abschnitte nicht möglich war. Wo der Farbenwechsel eintrat, fand er sich hauptsächlich an dem innerhalb der Saftbahnen des Bindegewebes in dem Tumor und in seiner Umgebung liegenden Pigment, seltener an dem des Sarcomgewebes selbst, obwohl sich dieses seiner äusseren Erscheinung nacb nicht im mindesten von dem reagirenden unterschied.

Urtheilt man allein nach dem Aussehen des amorphen Pigmentes der melanotischen Tumoren, so vereinigt sich Vieles, um zu der Ueberzeugung zu führen, dass das Melanin nichts Anderes, als ein metamorphosirtes Hämoglobin ist. In der oft schwärzlichbraunen, sepiaähnlichen Farbe desselben kann ich nicht, wie v. Recklinghausen annimmt, ein charakteristisches Merkmal finden, wodurch es vor dem hämatogenen Pigment ausgezeichnet ist. Das Melanin verdankt seinen Namen dem makroskopischen Aussehen und verdient ihn auch nur hierdurch; durch das Zusammenwirken einer grossen Summe von Körnchen wird der Eindruck des Schwarzen oder Rauchgrauen erweckt; das Mikroskop dagegen löst die Heerde in einzelne Elemente auf, welche oft keine Spur einer schwärzlichen Beimischung besitzen, sondern die reine goldgelbe oder kupferähnliche Farbe, welche den typischen Hämoglobinderivaten eigen ist. Andererseits fand ich schon innerhalb der Zeitgrenzen, welche meine Versuche an Kaninchen umfassten, bisweilen, wenn auch nicht oft, an notorisch hämatogenem Pigment jenen schmutzigen, schwärzlichen Anflug auftreten. Ich möchte den Farbenton allein schon als Hinweis auf den hämatogenen Ursprung ansehen; dazu kommt, dass die Gestalt und der Cmfang der einzelnen "Melanin"Körner, sowie ihre Zusammenorduung zu Gruppen innerhalb oder ausserhalb von Zellen, welche die verschiedensten Grössensorten umfassen, im höchsten Grade an das erinnert, was in jeder Ansammlung von Blutpigment wiederkehrt.

Die Localisation des Melanins innerhalb der Tumoren hat 
Langhans geltend gemacht als Gegenbeweis dessen, dass die Sarcomzellen selbst durch eine specifische Thätigkeit metabolisch dasselbe erzeugen, weil man für diese letztere nicht eine so ungleiche Vertheilung annehmen könnte, wie sie in der Anordnung des Pigmentes ausgesprochen wäre. Langhans glaubt, dass von den Blutgefässen aus das Material in Form rother Blutkörperchen geboten wird, welche durch Diapedese das Lumen verlassen und von Sarcomzellen aufgenommen werden, und dass diese eine ihnen nicht specifische, sondern allen „blutkörperchenhaltigen" Zellen eigene Thätigkeit ausüben, indem sie ihren Inhalt in amorphes Pigment umwandeln. Die nothwendigen Bedingungen für die ausgedehnte Diapedese sieht Langhans erfüllt in der histologischen Structur der Melanosarcome, dem Reichthum an Gefässen, der Weite derselben und ihren dünnen Wandungen.

Fasst man Laughans' Anschauung weit und sieht in der äusseren Erscheinung des Pigmentes einen Fingerzeig für die Herleitung rom Blutfarbstoff und in der Vertheilung innerbalb des Tumors einen Hinweis auf den räumlichen Ursprung aus den Blutgefässen, so möchte ich derselben vollkommen beitreten und als eine weitere Stütze dieser Ansicht das Resultat der mikrochemischen Eisenreaction binzufügen. Man trifft in fast allen melanotischen Sarcomen einen Theil des Farbstoffes, welcher sich für dieselbe empfänglich zeigt, welcher allerdings gegenüber den sie ablehnenden Körnern in den Hintergrund tritt. Dass dieser Bestandtheil kein fremder, etwa durch Hämorrhagien hinzugekommener, sondern genetisch mit der Hauptmasse des Pigmentes gleichbedeutend ist, dafür bürgt sowohl seine äussere Erscheinung, die in Grösse, Farbe und Glanz vor der Reaction durch nichts ausgezeichnet ist, als seine Localisation, welche die ihm zugehörigen Elemente mit nicht reagirenden Körnern in dieselbe Gruppe, oft sogar dieselbe Zelle zusammengeführt hat. Durch die Thatsache, dass das Hämosiderinstadium vergänglich ist, und mit dem zunehmenden Alter schwindet, gewinnt das Vorhandensein einer, wenn auch bur kleinen Quantität reagirenden Pigmentes neben einer grösseren Menge von gleichgestaltetem, aber reactionslosem eine andere Bedeutung, als die einer zufälligen Beimischung, dasselbe erscheint als ein gleichwerthiger, nur jüngerer 
Theil des Ganzen, an welchem allein sich noch der Charakter des gesammten Pigmentes als Hämoglobinderivat manifestirt. Unter Anwendung meiner experimentellen Erfahrungen auf die melanotischen Tumoren möchte ich das in Farbe, Gestalt und Anordnung durchaus mit dem hämatogenen übereinstimmende Pigment derselben, soweit es nicht mikrochemisch nachweisbares Eisen enthält, als ein im späten Stadium, jenseits der Grenze der Hämosiderinperiode befindliches Blutpigment ansehen.

Indessen ist damit für eine befriedigende Erklärung nicht genug gethan. Die Melanosarcome besitzen ein stetiges und meist rasches Wachsthum; wenn das Melanin in loco gebildet würde derart, dass von den Blutgefässen das Material, das Hämoglobin, geboten wird und innerhalb des Geschwulstgewebes seine Metamorphose durchläuft, so müsste man erwarten, dass in den jüngeren Abschnitten fortwährend eine Neubildung frischen Pigmentes, welches sich als solches durch die ausgicbige Empfänglichkeit für die Eisenreaction documentirt, in reichlicherem Maasse vor sich geht, als es in der That der Fall ist. Einen Schritt weiter führt die Berücksichtigung der topographischen Vertheilung des Farbstoffes. Wie hervorgohoben wurde, nimmt das durch die Geschwulst ziehende indifferente Bindegewebe, der Träger der Gefässe, an der Pigmentirung Theil, nicht etwa in untergeordnetem Grade, vielmehr ist bisweilen die überwiegende Menge in ihm localisirt, während die Sarcomzellen nur relativ wenig Körner enthalten; und weiterhin erstreckt sich die Verfärbung über die Grenzen des Tumors hinaus auf eine mehr oder weniger breite Zone des in seiner Structur normalen Gewebes. In diesen Bezirken gehört das Pigment zum Theil den fixen Zellen an, zum grösseren aber liegt es in den Lymphspalten, die dadurch bedeutend ausgedehnt werden und als meist parallele braune Streifen erscheinen. Bald sind diese perlschnurartig zusammengesetzt aus aneinandergereihten himbeerförmigen Häufchen, die wohl bisweilen eine Zelle erfüllen, wie der darin gelegene färbbare Kern andeutet, häufiger aber frei sind; bald entstehen sie durch gleichmässige Nebeneinanderordnung einzelner Körner. Mit Vorliebe folgt das Pigment dem Verlauf der Ge- 
fässe; der Querschuitt derselben erscheint oft von einem braunen Ring umschlossen; hier sind es die Lymphspalten der Adventitia, welche als Vermittler zwischen denen des umgebenden Bindegewebes und dem Gefässlumen die Körner beherbergen. In den Bindegewebssepten innerhalb des Tumors selbst ist die Vertheilung die gleiche. Die Aeste, welche von den Gefässen derselben zwischen die einzelnen Geschwulstalveolen eindringen, besitzen capillären Charakter, stellen ein einfaches Endothelrohr dar, von dessen Aussenfläche sich die Sarcomzellen erheben. Sehr bemerkenswerth ist es, dass diese Endothelien selbst nicht selten mehr oder weniger zahlreiche Körner einschliessen, und dass sich bisweilen im Lumen selbst $z$ wischen den Blutkörperchen amorphe braune Massen finden. Innerhalb der Alveolen liegt der grösste Theil des Farbstoffes im Protoplasma der Geschwulstzellen, aber eine oft beträchtliche Menge auch zwischen diesen als vereinzelte, reihenweise gestellten Körnchen, oder als Gruppen von solchen; Langhans sieht diesen freiliegenden Theil als frei geworden an durch Zerfall der Träger.

Die Pigmentirung eines den Lmfang des Geschwulstgewebes weit überschreitenden Bezirkes macht es zweifellos, dass die Pigmentbildung kein localer Prozess ist. Zar richtigen Würdigung dieser Vertheilung führt der Vergleich mit den Bildern, welche v. Recklinghausen, J. Arnold und Thoma nach Injection von Farbstoffen in's Blut eintreten sahen. Durch diese Versuche ist das Netz der Saftbahnen plastisch dargestellt worden, welche den Verkehr zwischen dem Blatgefässinhalt und den Geweben vermitteln und welcho den vorgeschriebenen, regelmässig betretenen Weg aller Farbstoffe bilden, welche in das Blut gelangen. Die Injectionsbilder dieses Kanalsystems, welche Arnold auch am lebenden Object sich entwickeln sah, wiederholen sich in der Anordnung des Pigmentes der melanotischen Tumoren und führen mich zu dem Schluss, dass dasselbe auf dem Blutweg in die Geschwulst transportirt wird, in den kleinsten Gefässen zwischen den Endothelien hindurch das Lumen verlässt und in die Saftspalten des Gewebes eintritt, innerhalb deren es zu den Sarcomzellen gelangt, um zum Theil von ihnen aufgenommen zu werden. Damit wird das Desiderat hinfällig, dass regelmässig ein 
gewisser Theil davon mikrochemisch nachweisbares Eisen enthält; es braucht keine Gesetzmässigkeit in der Reaction zu herrschen und auch ein vollständiger Mangel derselben bleibt erklärlich, denn ihr Grad wird davon abhängen, woher das Pigment kommt, von der Länge der Zeit, welche es vor seinem Eintritt in die Geschwulst schon existirt hat.

Diese Annahme einer Pigmentverschleppung auf dem Blutwege findet eine Stütze in einer Reihe von Beobachtungen, welche in der Literatur niedergelegt sind und in welchen zugleich die Quelle des Pigments offenbar oder doch zu vermuthen war. Abgesehen von den Nitheilungen von Tillmanus ${ }^{1}$ ) und Hindenlang ${ }^{2}$ ), wo die Residuen von Hämorrhagien nicht nur nach den abhängigen Lymphdrüsen, sondern auch nach inneren Organen, besonders der Leber transportirt wurden, giebt es Fälle, welche die melanotischen Tumoren näher berühren. Klar liegt der Vorgang der Verschleppung, wenn von einem primären Tumor gefärbte Geschwulstmetastasen entstehen und zwischen diesen Heerde von Melanin innerhalb eines Gewebes, das nicht die geringste Veränderung der Structur zeigt. Wagner ${ }^{3}$ ) beschreibt einen aus einem congenitalen Nävus der Haut entstandenen "Pigmentkrebs", welcher neben secundären Knoten "krebsigen" Charakters in Myocard und Pericard, Nebennieren, Leber und Muskeln in Myo-, Endo- and Pericard und der Niere in Form umschriebener schwarzer Heerde metastasirte, welche nur Pigment in und zwischen den durchaus unveränderten Bindegewebszellen enthielten. Hier ist es ausgeschlosssn, dass das Sarcom vermöge seiner Gefässanordnung und Beschafienheit die Extravasirung der Blutkörperchen veranlasst und dieselben metamorphosirt. In anderen Fällen ging mit dem Auftreten eines melanotischen Tumors Pigmentverarmung anderer Körperstellen einher: Virchow ${ }^{4}$ ) berichtet eine von Fergusson herrührende Beobachtung, dass im Laufe eines Jahres die schwarzbraunen Haare eines Patienten weiss wurden, während sich eine mehrmals recidivirende mela-

1) Tillmanns, Archiv f. Heilkunde. 1878.

2) Hindenlang, a. a: O.

3) E. Wagner, Fall von Combination eines Pigmentkrebses mit einer reinen Pigmentgeschwulst. Arch. f. Heilkunde. Bd. V. 1864.

4) Virchow, Geschwülste. Bd. II. S. 275.

Arehiv f. pathol. Anat. Bd. 115. Hft. s. 
notische Geschwalst entwickelto. Dem ähnlich ist Iangen beck's') Fall, in welchem mit dem Wachsthum eines pigmentirten Tumors das Erblassen eines Nävus zusammenfiel. Diesen Vorgängen stellt Virchow die Melanosarcomentwickelung bei Pferden an die Seite; ron ihnen disponiren am meisten zu der Erkrankung diejenigen, welche mit farbiger Haut geboren wurden und erst durch den Verlust des Pigmentes zu Schimmeln geworden sind.

Neben diesen Füllen, in welchen ein Pigmentaustausch velschiedener Organe bezw. Körperstellen stattfindet, ist an die zu denken, in welchen mit dem Entstehen eines Melanosarcoms abnorme Verfärbung anderweitiger Organe in grösserer Ausdehnung verbunden ist. In einer Mittheilung von Oppenheimer ${ }^{2}$ ) betrifft bei bestehendem Melanosarcom der Haut die übermässige Pigmentirung einen grossen Theil der übrigen Haut mit dem Fettgewebe, die Schleim- und serösen Häute, die Knochen. Eine dunklere Bräunung der Haut fand Rindfleis $\mathrm{ch}^{3}$ ) eintreten bei einem Melanosarcom des Knochenmarkes mit Metastasen in den inneren Organen, und auch in dem erwähnten Falle von Wagner war die Haut des ganzen Körpers „bläulichgrau“ verfärbt. Analoge Erscheinungen enthält die Mittheilung von Orsi Fran-

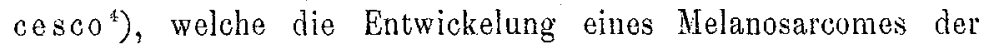
Hant aus einom congenitalen Nävus in Verbindung mit starker Verfärbung der Pia mater und der Hirnrinde betrifft. Endlich mag nicht unerwähnt bleibeo, dass einige Beobachtungen existiren, nach denen sehr grosse Nävi ohne Sarcombildung mit abnormer Pigmentirung der weichen Hirnhäute einhergingen. Planner ${ }^{5}$ ) beschreibt einen solchen Fall und citirt einen analogen, welchen Rokitanski beobachtet hatte.

In diesen Fällen wird die diffuse Pigmentirung der Organe nicht als eine vom primären Heerd ausgehende Metastase auf-

1) Langenbeck, Deutsche Klinik. 1860. cit. v. Virchow ibid.

2) Oppenteimer, a. a. 0 .

3) Rindfleisch u. Harris, Eine melanotische Geschwulst des Knochenmarkes. Dieses Arcbiv Bd. 103. 1886.

4) Orsi Francesco, Gaz. med. ital. lombard. Cit. von

5) Planner, Ein Fall von Naevus congen. mit excessiver Geschwulstbildung. Vierteljabrschr. f. Dermatol. u. Syphilis. 1887. 
gefasst werden können. Vielmehr scheint im Körper eine Ucberproduction von Farbstoff stattzufinden, welcher ebenso in der Geschwulst, wie in den übrigen Geweben deponirt wird.

Vielleicht gelingt es, noch für andere Pigmente, deren mangelnde Eisenreaction bisher ihre Einreihung in die autochthonen veranlasst hat, diesen Mangel durch den Nachweis zu erklären, dass sie nicht in loco gebildet werden, sondern in das Gewebe transportirt worden sind, nachdem sie bereits das Hämosiderinstadium überwunden hatten.

Dieser Gedanke an eine Verschleppung des Pigmentes ist auf Kosten der Anschauung von der localen Bereitung desselben für das Rete Malpighii in neuester Zeit durch Aeby ${ }^{1}$ ), Riehl $^{2}$ ), Ehrmann ${ }^{3}$ ), Nothnagel ${ }^{4}$ ), v. Kölliker ${ }^{5}$ ) und $\operatorname{Karg}^{6}$ ) in den Vordergrund gestellt worden. Zum Studium diente die Haut weisser Menschen, besonders unter abnormen Verhältnissen, welche mit einer dunkleren Färbung einhergehen, bei Morbus Addisonii, Gravidität, chronischer Lungonphthise, und die des Negers, und zum Vergleich wurde auch die der Wirbelthiere und Amphibien herangezogen. Die genannten Autoren suchen in dem Pigment des Corium die Quelle für das des Rete Malpighii, derart, dass ein stetiger Abfluss desselben nach der Oberfläche zu erfolgt, die Körner in die Saftspalten zwischen die Epithelien eindringen und schliesslich in das Protoplasma der letzteren selbst. Dieser Prozess steht dem für die melanotischen Tumoren statuirten nahe, nach welchem die Sarcomzellen ihren Farbstoff von dem die Geschwulst umgebenden und in sie eindringenden Bindegewebe beziehen. Ein Differenzpunkt liegt in dem Modus des Transportes: In der Haut werden allgemein Zellen, die "Chromatophoren", als Vermittler angesehen, welche

1) Aeby, Die Herkunft des Pigmentes im Epithel. Centralbl. f. d. med. Wissensch. 1885.

2) Riehl, Zur Kenntniss des Pigmentes im menschl. Haar. Vierteljahrschr.

f. Dermatol. u. Syphilis. Bd. XI. 1887. - Zur Pathologie des Morbus Addisonii. Zeitschr. f. klin. Med. 1886.

3) Ehrmann. Vierteljahrschr. f. Dermatol. u. Syphilis. 1880 .

4) Nothnagel, Zur Pathologie des Morbus Addisonii. Zeitschr. f. klin. Med. 1885.

5) v. Kölliker. Zeitschr. f. wissensch. Zoologie. 1887.

6) Ka rg, Studien über transplantirte Haut. Archiv f. Anat. u. Physiol. 1888. 
activ zwischen die Epithelion wandern, oder hineingeschwemmt werden (Karg), hier den intercellulären Räumen sich anpassend in weitverästigte Gebilde sich verwandeln und schliesslich mit ihrem Inhalt von den Epithelien aufgenommen werden. Die Präparate der melanotischen Tumoren boten reichliche Gelegenheit zu beobachten, dass der Einschluss der Farbstoffkörner in Zellen keine nothwendige Vorbedingung für ihre Weiterbeförderung ist, sondern dass sie in ebenso grosser Zahl frei, vereinzelt oder zu Häufchen geballt, in den Lymphspalten durch den Säftestrom fortgetuieben werden. Die Möglichkeit dieser Ortsbewegung unabhängig von Zellen besteht zweifellos, und es scheint mir, dass den letzteren für die Hautpigmentirung eine grössere Rolle zugeschrieben wird, als sie verdienen. An den Melanosarcomen, bei denen die äberziehende und umgebende Haut, ohne sonst verändert $z u$ sein, an der Pigmentirung theilnahm, fand ich im mikroskopischen Bilde zwischen den Epithelien feine Netze, welche sich aus braunen Körnern zusammensetzten, ohne dass sich jedesmal entscheiden liess, ob dieselben verästigten Zellen entsprachen; innerhalb der Cutis selbst aber, zwischen den Blutgefässen und der Epithelgrenze war deutlich zu erkennen, dass keine Gesetzmässigkeit in der Beziehung der Körner zu den Zellen herrschte, dass ein nicht geringerer Theil frei zwischen diesen, als in ihrem Protoplasma lag. Demselben Verhältniss begegnete ich in circumscripten Pigmentflecken und ausgedehnten gebräunten Hantpartien. Die Entstehung des Farbstoffes verlegen die genannten Autoren in das Corium selbst: Karg nimmt für die Negerhant eine Dunkelfärbung präexistenter weisser Granula "aus noch unbekannten Gründen" an, welche wohl mit der Blutzufuhr im Zusammenhang steht, aber mit dem gewöhnlichen Vorgang der Pigmentbildung nichts gemeinsam hat. An dem letzteren halten die Uebrigen fest; sie lassen in der Cutis farbige Blutkörperchen aus den Capillaren auswandern, die Metamorphose durchlaufen und nach Vollendung derselben als Pigmentkörner in das Epithel eindringen; Riehl konnte bei Morbus Addisonii in der Adventitia der Gefässe und ihrer Umgebung Blutextravasate und „blutkörperchenhaltige" Zellen nachweisen. In der That hat der Farbstoff der Haut, was auch von Demiéville ${ }^{1}$ ) für die Nävi

1) Demiéville, Ueber die Pigmentflecken d. Haut. Dies. Arch. Bd.81. 1880. 
betont wird, mit den gewöhnlichen Hämoglobinderivaten die grösste Aehnlichkeit sowohl der morphologischen Beschaffenheit, als seiner Anordnung nach. Jedoch haftet der Anuahme seiner Bildung aus den Blutscheiben in der Cutis selbst dasselbe Bedenken an, welches sich gegen die der localen Entstehung in melanotischen Tumoren erhob: Man müsste erwarten, dass constant ein grosser Theil der Körner mikrochemisch nachweisbares Eisen enthielte; in Wirklichkeit aber verhalten sich dieselben fast stets vollständig ablehnend gegen die Reaction, wie ich mich selbst an einer ganzen Reihe verschiedenartiger Präparate überzeugt habe. Mit Rücksicht auf die von fast allen Autoren hervorgelobene Lagerung um die Gefässe, hat es viel Wahrscheinlichkeit, dass das Pigment nicht innerhalb der Haut selbst entsteht, sondern ihr auf dem Blutwege zugeführt wird und in der Cutis die Gefässbahn verlässt, um in die Lymphspalten überzutreten.

Als ein weiteres Beispiel für denselben Modus des Transportes glaube ich die Substantia nigra der Grosshirnschenkel ansehen zu dürfen nach den Beobachtungen, welche eine Reihe darauf untersuchter Fälle ergeben haben. Die Hauptmasse des Farbstoffes, welcher durchweg in körniger Form auftritt, gehört den Ganglienzellen an; er nimmt in diesen bald die Gegend eines Poles ein, bald erfüllt er das ganze Protoplasma, bald erscheint die Zelle nur leicht gesprenkelt. Durch seine Farbe unterscheidet er sich in keiner Weise von den Hämoglobinderivaten; vorherrschend ist ein glänzender rothbrauner, seltner goldgelber Ton; dagegen weicht die Form von dem gewöhnlichen Bilde derselben $a b$ : Einmal bestelien nur geringe Grössenschwankungen zwischen den einzelnen Körnern, dieselben zeigen alle annähernd das gleiche Volumen, und andererseits ist dieses $V_{0}-$ lumen ein sehr. kleines; die gleichgefärbten grösseren runden und eckigen Schollen sind relativ selten; wo sie vorkommen, liegen sie mitten unter den feinkörnigen Massen innerhalb derselben Zelle. Die Ganglienzellen sind nicht die alleinigen Träger des Pigmentes, das Gliagewebe selbst nimmt an der Verfärbung Theil: Die Hauptmasse der diesem angehörigen Körner trägt dem äusseren Ansehen nach das typische Gepräge der Abkömmlinge des Hämoglobins: Ess sind die bekannten goldgelben bis 
rothbraunen runden und eckigen Gebilde von reinem Glanz, die bisweilen bis zum doppelten Umfang eines rothen Blukörperchens heraureichen; auch ihre Gruppirung zu Häufchen, die frei oder in kleinkernige Wanderzellen eingeschlossen liegen, trägt den Stempel des hämatogenen Ursprunges. Ein geringerer Antheil dieses Pigmentes gleicht in seiner regelmässigen feinen Körnung dem in den Ganglienzellen enthalteneu; auch dieses liegt vielfach frei, dann in der Regel als unregelmässig gestalteter Haufen, oder in Zellen eingeschlossen, die theils ausgesprochen leukocytären Charakters sind, theils aber einen auffallend grossen Protoplasmaring mit oder ohne scharfe Begrenzung besitzen. Diese beiden Grössenformen werden oft innerhalb derselben freiliegenden Gruppe, oder in derselben Pigmentzelle neben einander getroffen, bald so dass in einem staubähnlichen Heerd nur eine oder wenige umfangreichere Schollen liegen, bald so, dass die letateren das vorherrschende Element sind and der Raum zwischen ihnen von Angehörigen der kleinen Form ausgefïllt wird. Mit Vorliebe hält sich das Pigment an die Blutgefässe; bei denen von etwas grösserem Kaliber ist die adventitielle Scheide davon durchsetzt, bei den kleineren, welche nur ans einem Endothelrohr bestehen, schliessen sie sich direct an dieses an, und wenn man Gelegenheit hat, ein solches auf eine weitere Strecke zu verfolgen, sieht man seiner Wandung nach aussen hin überall pigmentbeladene Zellen und freie Körner aufsitzen. Von den Gefässen aus vertheilt sich der Farbstoff in das Gewebe und hält sith hier auffallend häufig in der Nähe der Ganglienzellen auf; bisweilen schmiegen sich die mit ihm gefülten Wanderzellen denselben so eng an, dass deren Protoplasma eingebuchtet wird.

Die Constanz des Befundes bürgt dafür, dass das Pigment ausserhalb der Ganglienzellen keine zufällige, bedeutungslose $\mathrm{Er}$ scheinung ist. Liegt in der morphologischen Beschaffenheit der grösseren Schollen schon eine Wahrscheinlichkeit für ihren hämatogenen Ursprung und in ihrer räumlichen. Vermischung mit den feinen Körnchen sowohl in den Ganglienzellen als im Gliagewebe die für eine innere Verwandtschaft der beiden Formen, so giebt der Erfolg der Eisenreaction die Sicherheit für Beides. Von den längs der Gefässe oder mitten im Gewebe liegenden gelbbraunen Körneru, gleichviel ob frei, oder in Zallen, ist ein grosser 'Theil 
für die Reaction empfänglich und zeigt alle verschiedenen Grade des Farbenwechsels bis zum gesättigten Blau; ein anderer Theil bleibt unverändert. Auch von den staubförmigen Körnchen nehmen einige die Bläuung an, während die meisten, oft mit diesen zu derselben Gruppe zusammengefügten, ihre ursprüngliche Färbung beibehalten. Der Inhalt der Ganglienzellen selbst widersteht fast durchweg der Reaction, doch trifft man ihn ab und zo ganz oder theilweise präcis den Farbenwechsel eingehen.

Es scheint durch diese morphologischen und chemischen Thatachen eine Kette von Uebergangsstufen hergestellt, deren Anfangsglied das im Gewebe liegende grobkörnige Hämosiderin, deren Endglied das nicht auf Eisen reagirende feinkörnige „autochthone" Pigment der Ganglienzellen ist und welche räumlich den Zusammenhang der letzteren mit den Gefässen herstellt. Es geht daraus hervor, dass die Substantia nigra ihren Farbstoff nach denselben Gesetzen bekommt, welche für die melanotischen Sarcome als wahrscheinlich hingestellt wurden, dass die Ganglienzellon selbst denselben weder metabolisch, noch aus dem Hämoglobin bilden, sondern nur das aufnehmen, was ihnen auf dem Blut-und Lymphweg zugeführt wird und hämatogenes Pigment ist, welches seine Eisenreaction zum Theil schon wieder eingebüst hat. 